\title{
System Characterization Report on Planet's Dove Classic
}

Chapter C of

System Characterization of Earth Observation Sensors

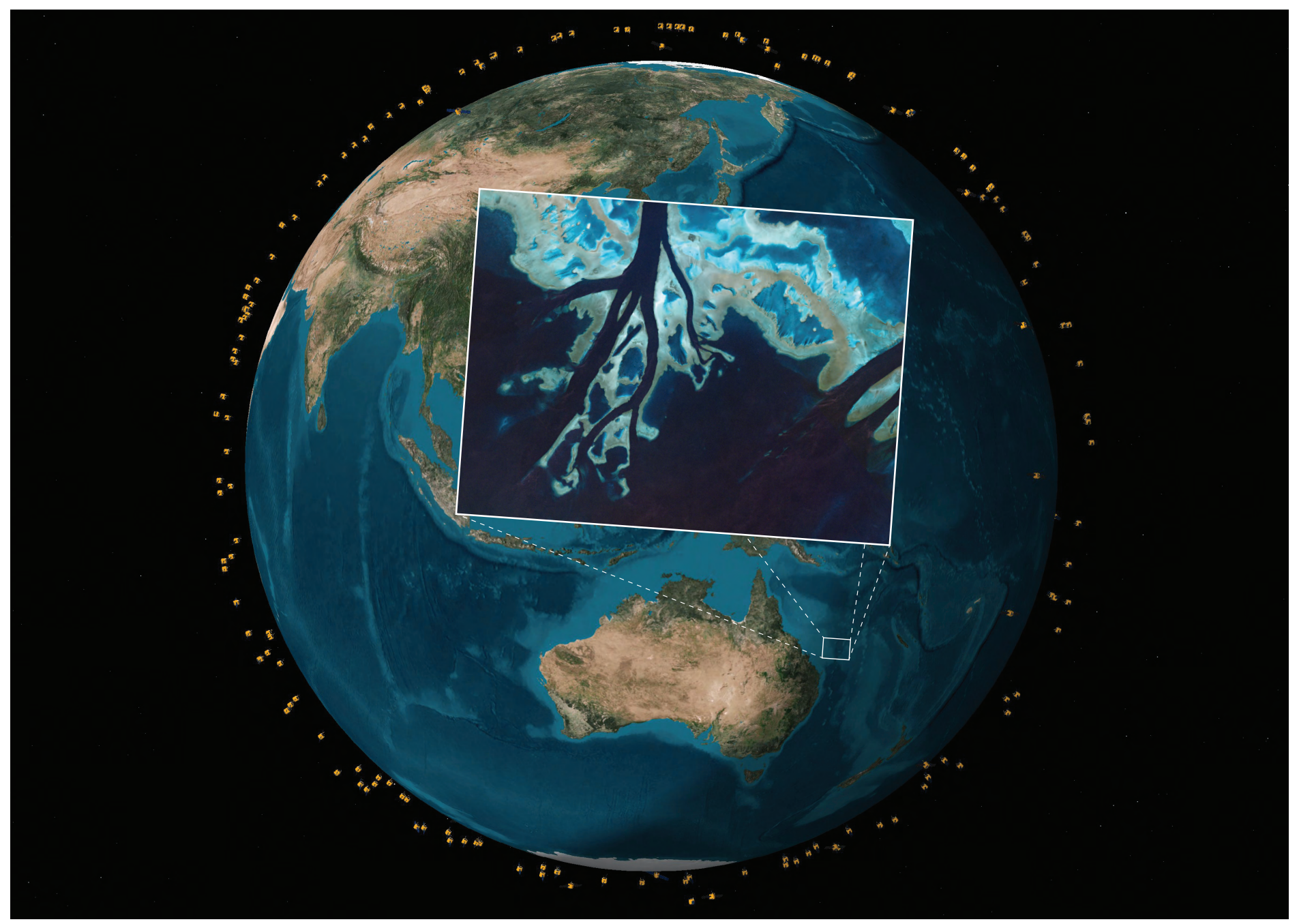

Open-File Report 2021-1030-C 
Cover: Satellite image of the Great Barrier Reef, Australia, taken July 8, 2016, using the Planetscope sensor. Image courtesy of Planet, licensed under the Creative Commons Attribution-NonCommercial 2.0 Generic license. An image showing the current (2021) operational Planet flock satellites, generated from Analytical Graphics, Inc., Systems Tool Kit. 


\section{System Characterization Report on Planet's Dove Classic}

By Minsu Kim, ${ }^{1}$ Seonkyung Park, ${ }^{1}$ Cody Anderson, ${ }^{2}$ and Gregory L. Stensaas ${ }^{2}$

Chapter C of

System Characterization of Earth Observation Sensors

Compiled by Shankar N. Ramaseri Chandra ${ }^{1}$

${ }^{1}$ KBR, Inc., under contract to the U.S. Geological Survey.

${ }^{2}$ U.S. Geological Survey.

Open-File Report 2021-1030-C 


\section{U.S. Geological Survey, Reston, Virginia: 2021}

For more information on the USGS - the Federal source for science about the Earth, its natural and living resources, natural hazards, and the environment—visit https://www.usgs.gov or call 1-888-ASK-USGS.

For an overview of USGS information products, including maps, imagery, and publications, visit https://store.usgs.gov/.

Any use of trade, firm, or product names is for descriptive purposes only and does not imply endorsement by the U.S. Government.

Although this information product, for the most part, is in the public domain, it also may contain copyrighted materials as noted in the text. Permission to reproduce copyrighted items must be secured from the copyright owner.

Suggested citation:

Kim, M., Park, S., Anderson, C., and Stensaas, G.L., 2021, System characterization report on Planet's Dove Classic, chap. C of Ramaseri Chandra, S.N., comp., System characterization of Earth observation sensors: U.S. Geological Survey Open-File Report 2021-1030, 28 p., https://doi.org/10.3133/ofr20211030C.

ISSN 2331-1258 (online) 


\section{Contents}

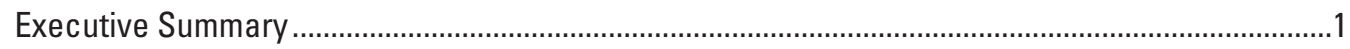

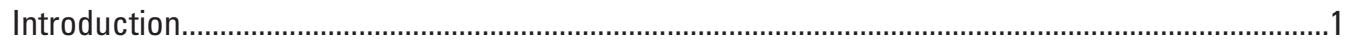

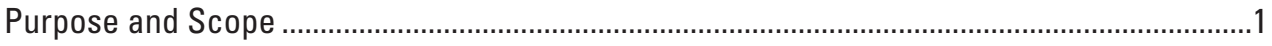

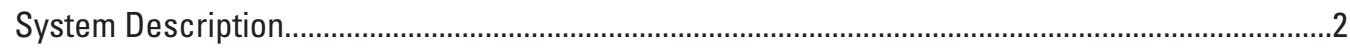

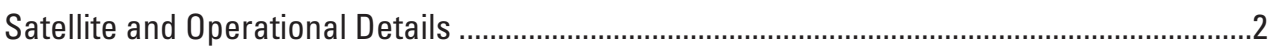

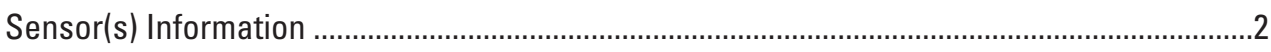

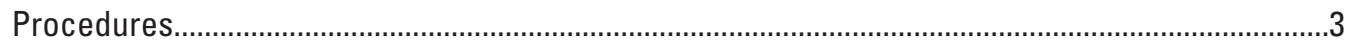

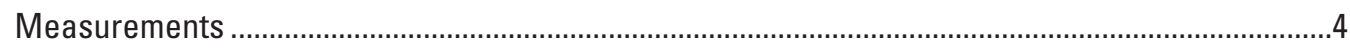

Analysis

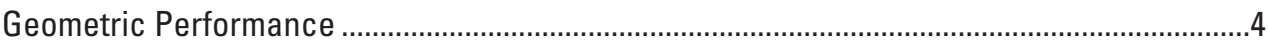

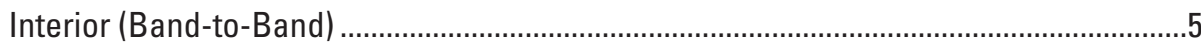

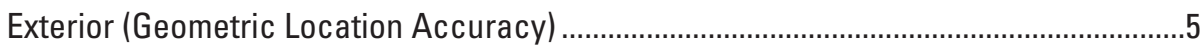

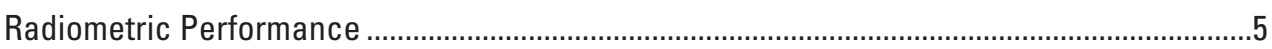

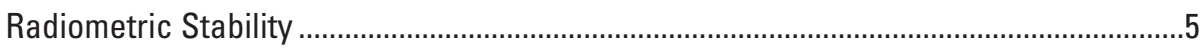

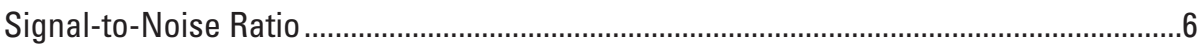

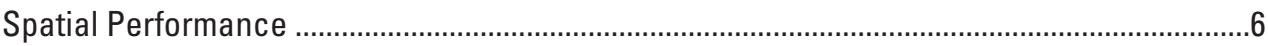

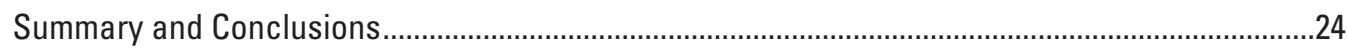

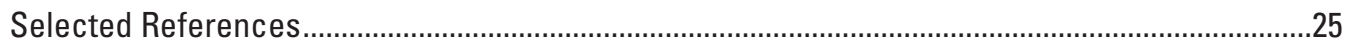

Appendix 1. Radiometric Data.............................................................................................

\section{Figures}

1. Graph showing Planet's Dove Classic relative spectral response.......................................3

2. Band 1 to band 2 geometric error map of Roswell, New Mexico …................................

3. Band 1 to band 2 geometric error histograms for easting and northing and error distribution for Roswell, New Mexico ................................................................................

4. Band 2 to band 3 geometric error map of Roswell, New Mexico ......................................8

5. Band 2 to band 3 geometric error histograms for easting and northing and error

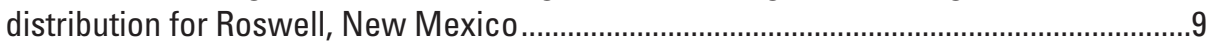

6. Band 3 to band 4 geometric error map of Roswell, New Mexico ....................................10

7. Band 3 to band 4 geometric error histograms for easting and northing and error distribution for Roswell, New Mexico ..........................................................................11

8. Relative geometric error map for Landsat 80 perational Land Imager and Planet's Dove Classic for Izmir, Turkey ..........................................................................12

9. Relative geometric error histograms for easting and northing and error distribution for Izmir, Turkey.

10. Graphs showing Top of Atmosphere reflectance comparison for Landsat 8 Operational Land Imager and Dove Classic, April 2017 scene pair .................................14

11. Graphs showing Top of Atmosphere reflectance comparison for Landsat 8 Operational Land Imager and Dove Classic, December 2017 scene pair...

12. Graphs showing Top of Atmosphere reflectance comparison for Landsat 8 Operational Land Imager and Dove Classic, August 2018 scene pair.

13. Graphs showing Top of Atmosphere reflectance comparison for Landsat 8 Operational Land Imager and Dove Classic, March 2019 scene pair 
14. Graph showing time series of Landsat 8 Operational Land Imager and Planet's

Dove Classic radiometric slope comparison

15. Graph showing time series of Landsat 8 Operational Land Imager and Planet's

Dove Classic radiometric offset comparison.

16. Dove-Classic image of calibration site at Baotou, China .

17. Graphs showing band 1 raw edge transects and shifted transects for Baotou, China

18. Graphs showing band 1 edge spread function and line spread function and modulation transfer function for Baotou, China

19. Graphs showing band 2 raw edge transects and shifted transects for Baotou, China

20. Graphs showing band 2 edge spread function and line spread function and modulation transfer function for Baotou, China

21. Graphs showing band 3 raw edge transects and shifted transects for Baotou, China

22. Graphs showing band 3 edge spread function and line spread function and modulation transfer function for Baotou, China.

23. Graphs showing band 4 raw edge transects and shifted transects for Baotou, China

24. Graphs showing band 4 edge spread function and line spread function and modulation transfer function for Baotou, China

\section{Tables}

1. Satellite and operational details for Planet's Dove Classic .............................................2

2. Imaging sensor details for Planet's Dove Classic ...............................................................

3. U.S. Geological Survey measurement results ..............................................................

4. Band-to-band registration error...............................................................................

5. Geometric error of Planet's Dove Classic imagery relative to Landsat 8 Operational Land Imager.

6. Top of Atmosphere reflectance comparison of Landsat 80 perational Land Imager images against Planet's Dove Classic images....................................................13

7. Spatial performance of Planet's Dove Classic ...........................................................16

\section{Conversion Factors}

U.S. customary units to International System of Units

\begin{tabular}{|c|c|c|}
\hline Multiply & By & To obtain \\
\hline \multicolumn{3}{|c|}{ Length } \\
\hline inch (in.) & 2.54 & centimeter $(\mathrm{cm})$ \\
\hline inch (in.) & 25.4 & millimeter (mm) \\
\hline
\end{tabular}


International System of Units to U.S. customary units

\begin{tabular}{|c|c|c|}
\hline Multiply & By & To obtain \\
\hline \multicolumn{3}{|c|}{ Length } \\
\hline centimeter $(\mathrm{cm})$ & 0.3937 & inch (in.) \\
\hline meter (m) & 3.281 & foot $(\mathrm{ft})$ \\
\hline meter (m) & 1.094 & yard (yd) \\
\hline kilometer (km) & 0.6214 & mile (mi) \\
\hline \multicolumn{3}{|c|}{ Mass } \\
\hline kilogram (kg) & 2.205 & pound avoirdupois (lb) \\
\hline
\end{tabular}

\title{
Abbreviations
}

\author{
ECCOE Earth Resources Observation and Science Cal/Val Center of Excellence \\ GSD ground sample distance \\ JACIE Joint Agency Commercial Imagery Evaluation \\ OLI Operational Land Imager \\ SNR signal-to-noise ratio \\ USGS U.S. Geological Survey
}





\title{
System Characterization Report on Planet's Dove Classic
}

\author{
By Minsu Kim, ${ }^{1}$ Seonkyung Park, ${ }^{1}$ Cody Anderson, ${ }^{2}$ and Gregory L. Stensaas ${ }^{2}$
}

\section{Executive Summary}

This report addresses system characterization of Planet's Dove Classic satellites and is part of a series of system characterization reports produced and delivered by the U.S. Geological Survey Earth Resources Observation and Science $\mathrm{Cal} / \mathrm{Val}$ Center of Excellence. These reports present and detail the methodology and procedures for characterization; present technical and operational information about the specific sensing system being evaluated; and provide a summary of test measurements, data retention practices, data analysis results, and conclusions.

Since 2013, Planet has launched more than 360 Dove $3 \mathrm{U}$ CubeSats, where U stands for 10 -centimeter $(\mathrm{cm}) \times 10-\mathrm{cm}$ $\mathrm{x} 10-\mathrm{cm}$ stowed dimensions, each weighing about 5 kilograms. Since 2015, all Dove satellites have had four-band imagers with about a 4-meter (m) pixel ground sample distance. Since 2016, all Doves have been launched into Sun-synchronous orbits varying from 474 to 524 kilometers, with inclinations between 97 and 98 degrees. The Dove series satellites do not have orbit maintenance capabilities; thus, their orbits decay slowly over time, contributing to shorter lifetimes of about 3 years. More information on Planet satellites and sensors is available in the "2020 Joint Agency Commercial Imagery Evaluation-Remote Sensing Satellite Compendium" and from the manufacturer at https://www.planet.com/.

The Earth Resources Observation and Science Cal/Val Center of Excellence system characterization team completed data analyses to characterize the geometric (interior and exterior), radiometric, and spatial performances. Results of these analyses indicate that Dove Classic has an interior geometric performance in the range of $-0.218(-0.073$ pixel) to $-0.037 \mathrm{~m}(-0.012$ pixel $)$ in easting and $-0.167(-0.056$ pixel $)$ to $-0.111 \mathrm{~m}(-0.037 \mathrm{pixel})$ in northing in band-to-band registration, an exterior geometric error of -6.841 ( -2.280 pixels) in easting and $-6.235 \mathrm{~m}(-2.078$ pixels $)$ in northing offset in comparison to Landsat 8 Operational Land Imager, a radiometric performance in the range of -0.057 to -0.010 in offset and 0.963 to 1.298 in slope, and a spatial perfor-mance in the range of 2.77 to 3.35 pixels for full width at half maximum, with a modulation transfer function at a Nyquist frequency in the range of 0.003 to 0.010 .

${ }^{1} \mathrm{KBR}$, Inc., under contract to the U.S. Geological Survey.

${ }^{2}$ U.S. Geological Survey.

\section{Introduction}

Planet, Inc. is well known for launching reduced-mass Earth observation satellites, with its Dove satellites weigh-ing 5.8 kilograms (12.8 pounds). Each Dove is a $3 \mathrm{U}$ CubeSat, where U stands for 10 -centimeter $(\mathrm{cm}) \times 10-\mathrm{cm} \times 10-\mathrm{cm}$ stowed dimensions. The first prototype Doves were launched in April 2013, followed by at least 20 more successful launches in the 7 years since, each carrying a flock of multiple Dove satellites, for a total of more than 360 Dove satellites launched into orbit. Planet has used this frequent launch cadence to produce at least 17 builds, or generations, of Doves with various technological and operating improvements in each build, which has resulted in continual advancement in capability in the 7 years since the launch of the first Dove. All data are provided with permission from Planet through their standard data access portal.

The data analysis results provided within this report have been derived from approved Joint Agency Commercial Imagery Evaluation (JACIE) processes and procedures. JACIE was formed to leverage resources from several Federal agencies for the characterization of remote sensing data and to share those results across the remote sensing community. More information about JACIE is available at https://www.usgs.gov/ core-science-systems/eros/calval/jacie?qt-science_support_ page_related_con $=3 \#$ qt-science_support_page_related_con.

\section{Purpose and Scope}

The purpose of this report is to describe the specific sensor or sensing system, test its performance in three categories, complete related data analyses to quantify these performances, and report the results in a standardized document. In this chapter, the Dove Classic sensor is described. The performance testing of the system is limited to geometric, radiometric, and spatial. The scope of the geometric assessment is limited to testing the interior alignments of spectral bands against each other, and the exterior alignment is tested in reference to Landsat 8 Operational Land Imager (OLI).

The U.S. Geological Survey (USGS) Earth Resources Observation and Science Cal/Val Center of Excellence (ECCOE) project, and the associated system characterization process used for this assessment, follows the USGS Fundamental Science Practices, which include maintaining 
data, information, and documentation needed to reproduce and validate the scientific analysis documented in this report. Additional information and guidance about Fundamental Science Practices and related resource information of interest to the public are available at https://www.usgs.gov/ about/organization/science-support/office-science-qualityand-integrity/fundamental-science-practices. For additional information related to the report, please contact ECCOE at eccoe@usgs.gov.

\section{System Description}

This section describes the satellite and operational details and provides information about the Dove Classic sensor.

\section{Satellite and Operational Details}

The satellite and operational details for Dove Classic are listed in table 1.

\section{Sensor(s) Information}

The imaging sensor details for Dove Classic are listed in table 2. The relative spectral response for Dove Classic is shown in figure 1 .

Table 1. Satellite and operational details for Planet's Dove Classic.

[cm, centimeter; NIR, near infrared; km, kilometer; ${ }^{\circ}$, degree; \pm , plus or minus; $\mathrm{m}$, meter; $<$, less than]

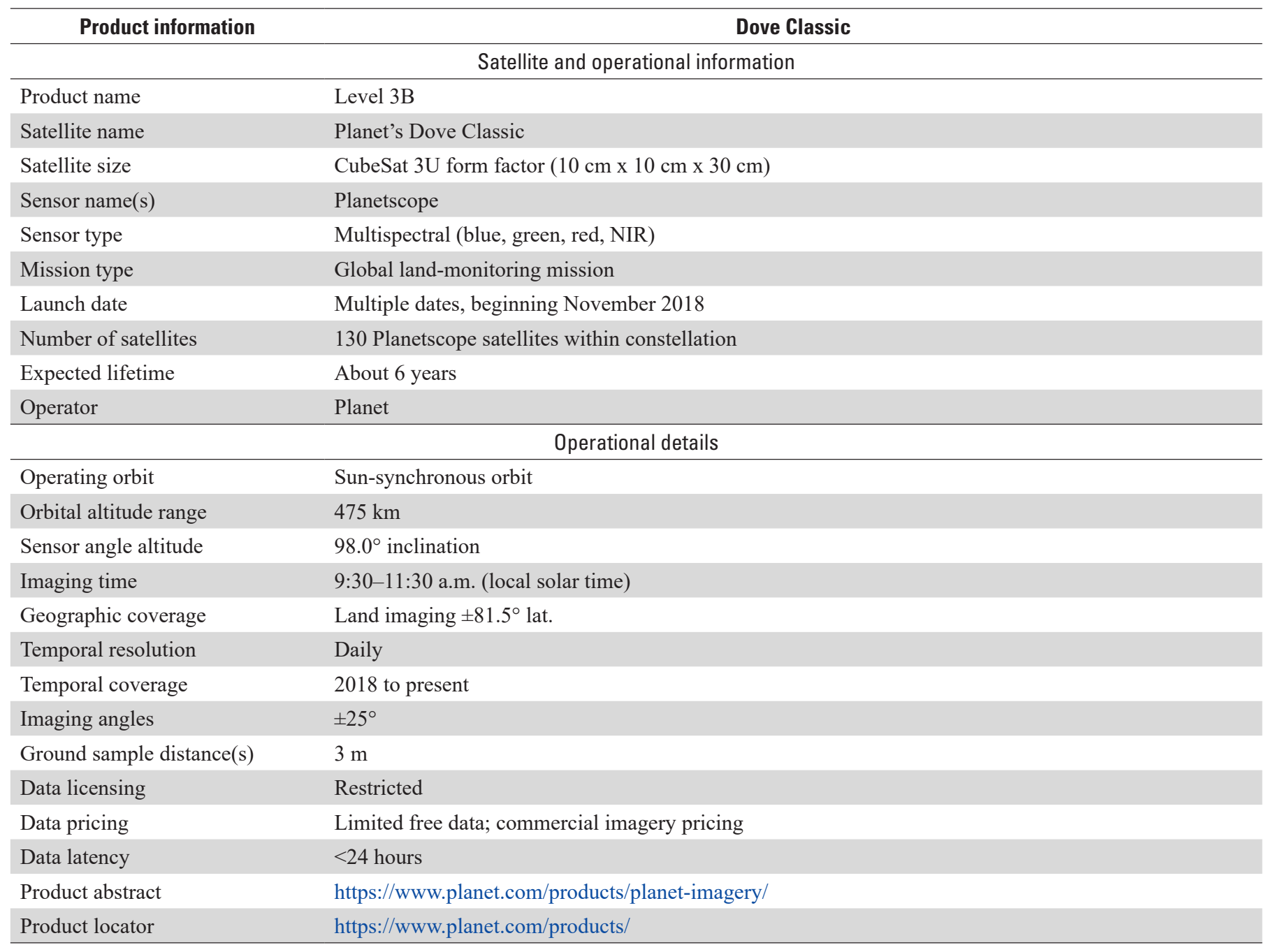


Table 2. Imaging sensor details for Planet's Dove Classic.

[Planetscope has a swath width of 8 kilometers; $\mu \mathrm{m}$, micrometer; $\mathrm{m}$, meter; NIR, near infrared]

\begin{tabular}{lcccc}
\hline \multirow{2}{*}{ Spectral band(s) details } & \multicolumn{4}{c}{ Dove Classic } \\
\cline { 2 - 5 } & Lower band $(\boldsymbol{\mu m})$ & Upper band $(\boldsymbol{\mu m})$ & $\begin{array}{c}\text { Radiometric resolution } \\
\text { (bits) }\end{array}$ & $\begin{array}{c}\text { Ground sample } \\
\text { distance }(\mathbf{m})\end{array}$ \\
\hline Band 1 - blue & 0.455 & 0.515 & 12 (scaled to 16) & 3 \\
Band 2-green & 0.500 & 0.590 & 12 (scaled to 16) & 3 \\
Band 3-red & 0.590 & 0.670 & 12 (scaled to 16) & 3 \\
Band 4-NIR & 0.780 & 0.860 & 12 (scaled to 16) & 3 \\
\hline
\end{tabular}

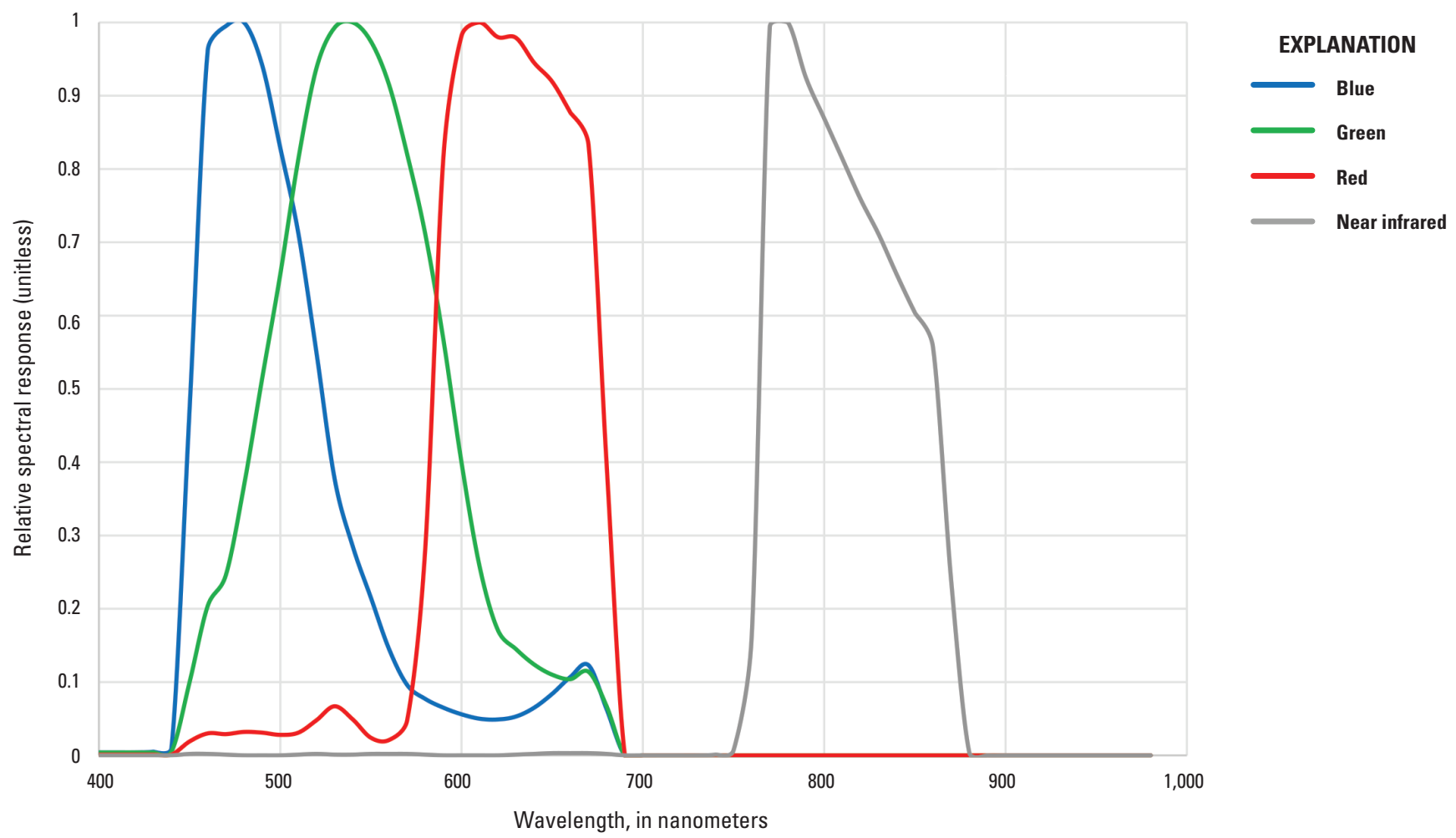

Figure 1. Planet's Dove Classic relative spectral response.

\section{Procedures}

ECCOE has established standard processes to identify Earth observing systems of interest and to assess the geometric, radiometric, and spatial qualities of data products from these systems.

The assessment steps are as follows:

- system identification and investigation to learn the general specifications of the satellite and its sensor(s);

- data receipt and initial inspection to understand the characteristics and any overt flaws in the data product so that it may be further analyzed;
- geometry characterization, including interior geometric orientation measuring the relative alignment of spectral bands and exterior geometric orientation measuring how well the georeferenced pixels within the image are aligned to a known reference;

- radiometry characterization, including assessing how well the data product correlates with a known reference and, when possible, assessing the signal-to-noise ratio (SNR); and

- spatial characterization, assessing the two-dimensional fidelity of the image pixels to their projected ground sample distance (GSD). 
Data analysis and test results are maintained at the USGS Earth Resources Observation and Science Center by the ECCOE project.

\section{Measurements}

The observed USGS measurements are listed in table 3. Physical error, in meters, is calculated by the GSD multiplied by the pixel error. Details about the methodologies used are outlined in the "Analysis" section.

\section{Analysis}

This section of the report describes the geometric, radiometric, and spatial performance of Dove Classic.

\section{Geometric Performance}

The geometric performance for Dove Classic is characterized in terms of the interior (band-to-band alignment) and exterior (geometric location accuracy) geometric analysis results.

Table 3. U.S. Geological Survey measurement results.

[USGS, U.S. Geological Survey; m, meter; RMSE, root mean square error; L8 OLI, Landsat 8 Operational Land Imager; Ltyp, typical radiance; RGB, red, green, blue; $\sim$, about; NIR, near infrared; FWHM, full width at half maximum; MTF, modulation transfer function]

\begin{tabular}{|c|c|}
\hline Description of product & Top of Atmosphere reflectance \\
\hline & USGS measurement results \\
\hline \multicolumn{2}{|c|}{ Geometric performance (easting, northing), in meters (pixels) } \\
\hline Exterior (geometric location accuracy) & $\begin{array}{l}\text { Mean: }-6.841 \mathrm{~m}(-2.280),-6.235 \mathrm{~m}(-2.078) \\
\text { RMSE: } 6.930 \mathrm{~m}(2.310), 6.561 \mathrm{~m}(2.187)\end{array}$ \\
\hline \multicolumn{2}{|r|}{ Radiometric performance (offset, slope) } \\
\hline $\begin{array}{l}\text { Radiometric evaluation (linear regression-Dove } \\
\text { Classic versus L8 OLI reflectance) }\end{array}$ & $\begin{array}{l}\text { Band } 1 \text { (offset, slope): }-0.010,0.963 \\
\text { Band } 2 \text { (offset, slope): }-0.029,1.063 \\
\text { Band } 3 \text { (offset, slope): }-0.042,1.208 \\
\text { Band } 4 \text { (offset, slope): }-0.057,1.298\end{array}$ \\
\hline Radiometric stability & $\begin{array}{l}\text { Overall radiometric characteristics were maintained over time (from April } 2017 \text { to } \\
\text { March 2019). Time series of radiometric comparison in terms of slope and offset are } \\
\text { provided in figures } 14 \text { and } 15 \text { in the "Analysis" section. }\end{array}$ \\
\hline Signal-to-noise ratio (SNR) (all median at Ltyp) & $\begin{array}{l}\text { Bands } 1-3 \text { (RGB): Mean SNR } \sim 30 \\
\text { Band } 4 \text { (NIR): Mean SNR } \sim 24\end{array}$ \\
\hline \multicolumn{2}{|r|}{ Spatial performance } \\
\hline Spatial performance measurement & $\begin{array}{l}\text { Band 1: FWHM }=2.77 \text { pixels; } \text { MTF at Nyquist }=0.010 \\
\text { Band 2: FWHM }=3.07 \text { pixels; MTF at Nyquist }=0.003 \\
\text { Band 3: } F W H M=3.07 \text { pixels; MTF at Nyquist }=0.007 \\
\text { Band 4: } F W H M=3.35 \text { pixels; MTF at Nyquist }=0.006\end{array}$ \\
\hline \multicolumn{2}{|r|}{ Known artifacts and quality issues } \\
\hline USGS noted artifacts/quality issues & $\begin{array}{l}\text { As predicted by the large line spread function (FWHM ranging from } 2.77 \text { to } 3.35 \text { pix- } \\
\text { els), the Dove Classic imagery does not have precise transition across a target edge. } \\
\text { Low SNR could affect quantitative measurements. }\end{array}$ \\
\hline
\end{tabular}




\section{Interior (Band-to-Band)}

For this analysis, each band of the Dove Classic image was registered against all other bands. Results from three images were gathered in table 4 to determine the mean error and root mean square error as listed in table 3 with results represented in pixels. Greater misalignment was seen with band 4 (near infrared), likely as a result of poorer spatial quality and its spectral distinctness from bands $1-3$. Together, the interior and exterior geometric analysis results, as reported in the "Interior (Band-to-Band)" and "Exterior (Geometric Location Accuracy)" sections, provide a comprehensive assessment of geometric accuracy. The band-to-band error in terms of error histograms and error distribution plot for three band combinations from the Roswell, New Mexico, scene (20180120_170400_0e2f) are presented in figures 2-7.

\section{Exterior (Geometric Location Accuracy)}

For this analysis, band 4 (infrared) of Dove Classic image (20190325_083005_0e2f_3B_AnalyticMS) and Landsat 8 OLI image (LC08_L1TP_180033_20190325_20190403 01_T1) for Izmir, Turkey, were compared to estimate relative geometric error. The results are listed in table 5 and the error grid is shown in figure 8 , the error histogram and error distribution is shown in figure 9 .

\section{Radiometric Performance}

For this analysis, 68 cloud-free regions of interest were selected from near-coincident Dove Classic system and Landsat 8 OLI scene pairs listed in appendix 1 . Once the relative georeferencing error between Landsat 8 OLI and Dove Classic has been corrected, Top of Atmosphere reflectance values from the two sensors are extracted. The scatterplots are drawn in a way that the $\mathrm{x}$-axis is the reference sensor and the $y$-axis is the comparison sensor. The linear regression, thus, represents Top of Atmosphere reflectance relative to that of the reference sensor. Ideally, the slope should be near unity and the offset should be near zero. For example, if the slope is greater than unity, that means the comparison sensor has a tendency to overestimate Top of Atmosphere reflectance compared to the reference sensor. Top of Atmosphere reflectance comparison results are listed in table 6 . The range of linear regressions coefficients for four bands using all scene pairs (appendix 1) are presented. Several selected radiometric comparison graphs using Landsat 8 OLI and Dove Classic scene pairs are shown in figures 10-13.

\section{Radiometric Stability}

For this analysis, figure 14 shows a time series of the slope of the radiometric comparison between Landsat 8 OLI and Dove Classic, as calculated. A time series of the offset of

Table 4. Band-to-band registration error (in pixels).

[ID, identifier; RMSE, root mean square error]

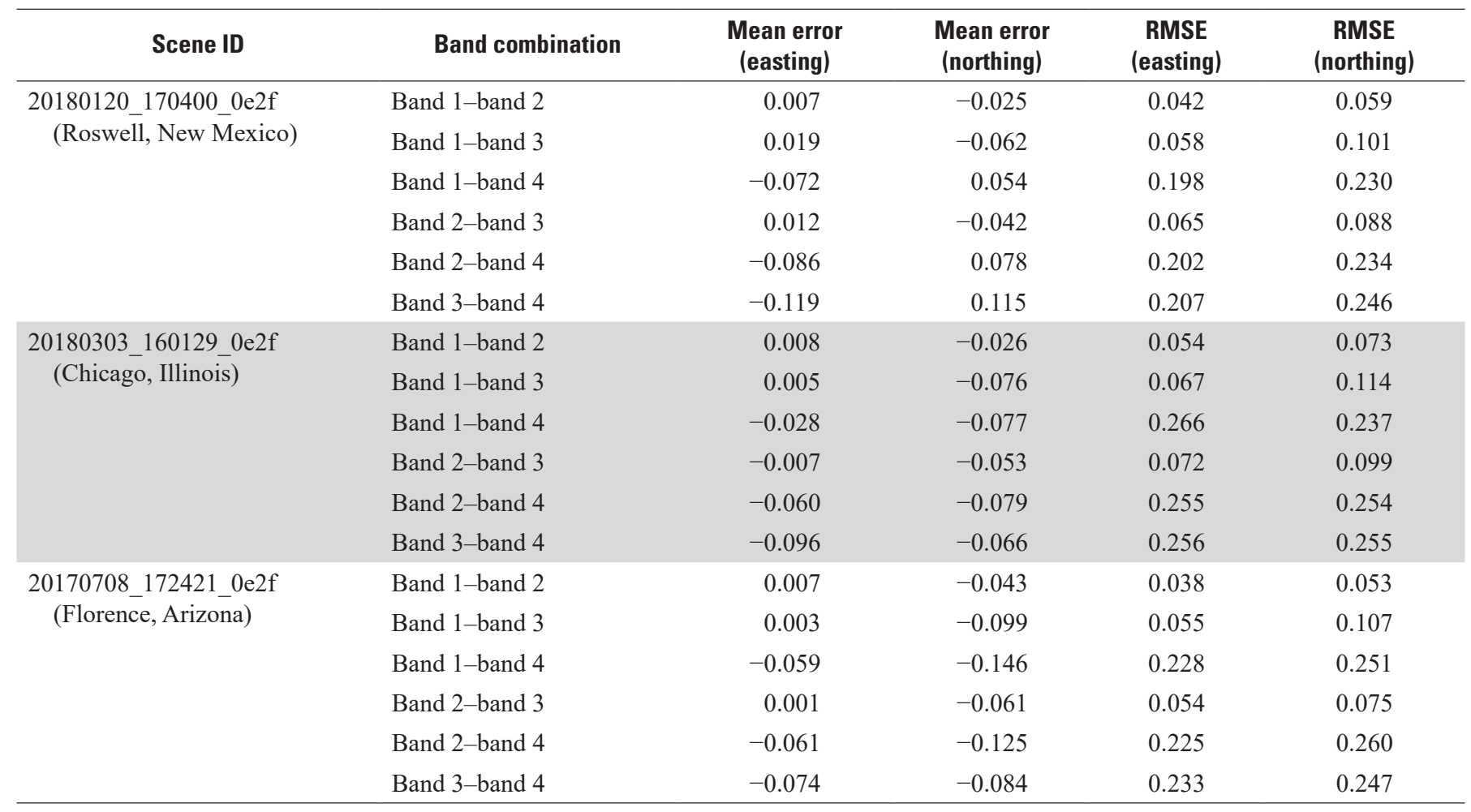




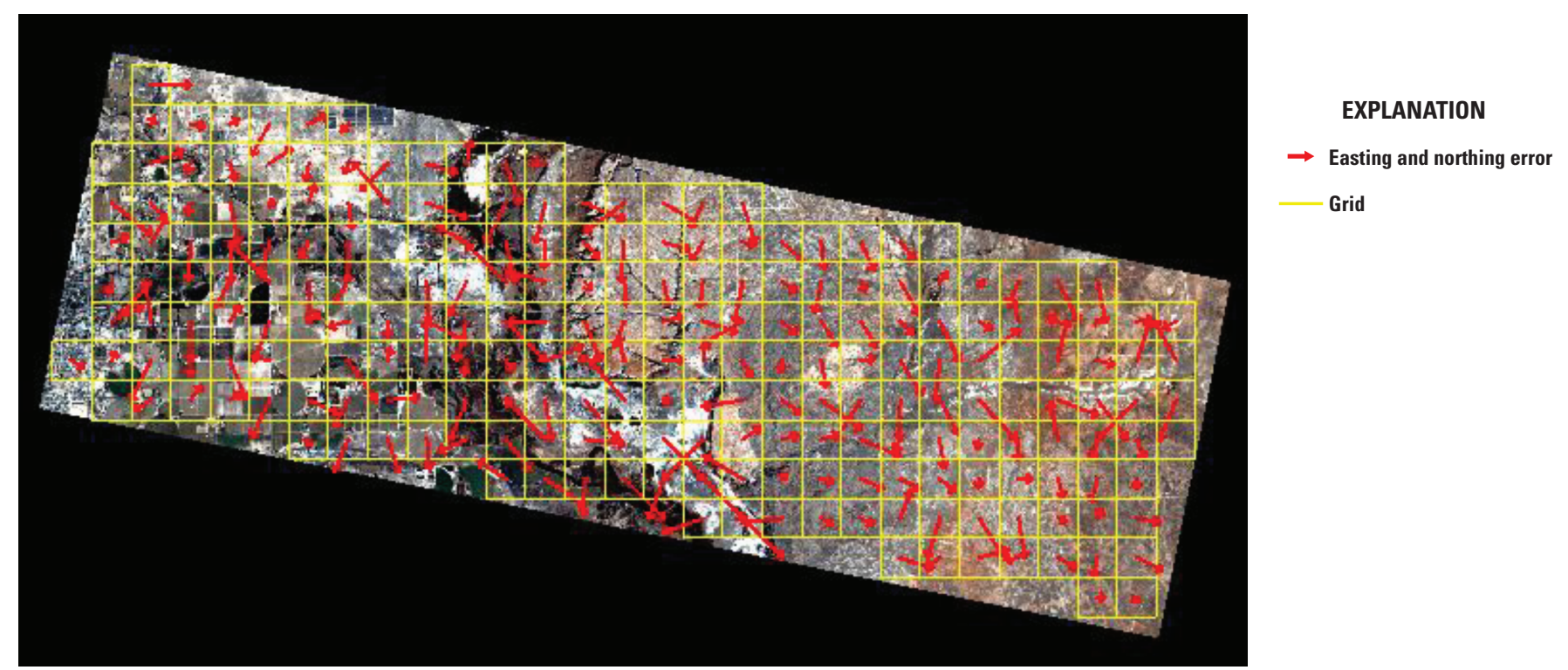

Figure 2. Band 1 (blue) to band 2 (green) geometric error map of Roswell, New Mexico.

the radiometric comparison between Landsat 8 OLI and Dove Classic is shown in figure 15. The datasets used to populate the time-series analysis results are detailed in appendix 1 .

\section{Signal-to-Noise Ratio}

The SNR was calculated using homogeneous areas adjacent to an edge target over the Baotou (China) Cal/Val site. The difference between the dark and bright area pixel values (commonly measured in terms of digital numbers) is divided by the one-sigma standard deviation noise level to get the SNR. SNR results are listed in table 3.

\section{Spatial Performance}

For this analysis, edge spread and line spread functions were calculated with resulting full width at half maximum and modulation transfer function at Nyquist frequency analysis output, as listed in table 7. The Dove-Classic image for the Baotou, China, $\mathrm{Cal} / \mathrm{Val}$ site used for the analysis is
“20200718_031215_0f28_3B_AnalyticMS.tif” and is shown in figure 16. The band 1 (blue) edge spread and line spread function results using the Baotou (China) Cal/Val site for analysis are shown in figure 17. The yellow box in figure 16 shows the edge transect bounding box. The results for band 1 (blue) are shown in figures 17 and 18. In figure 17, the dotted lines with diamond symbols are the raw transects. The green line is the middle transect, where the red dots are the region of the curve that is used for alignment. The lower plot in figure 17 is the aligned curve and the green line represents edge spread function. In the upper plot in figure 18, a white curve is an edge spread function with red line segment shows relative edge response; the green curve is a line spread function with a white line segment represents full width at half maximum. The lower plot in figure 18 is a modulation transfer function up to Nyquist frequency $(0.5)$ and the dashed line shows the frequency corresponding to the 50-percent modulation transfer function value. The results for band 2 (green) are shown in figures 19 and 20, the results for band 3 (red) are shown in figures 21 and 22, and the results for band 4 (near infrared) are shown in figures 23 and 24. 

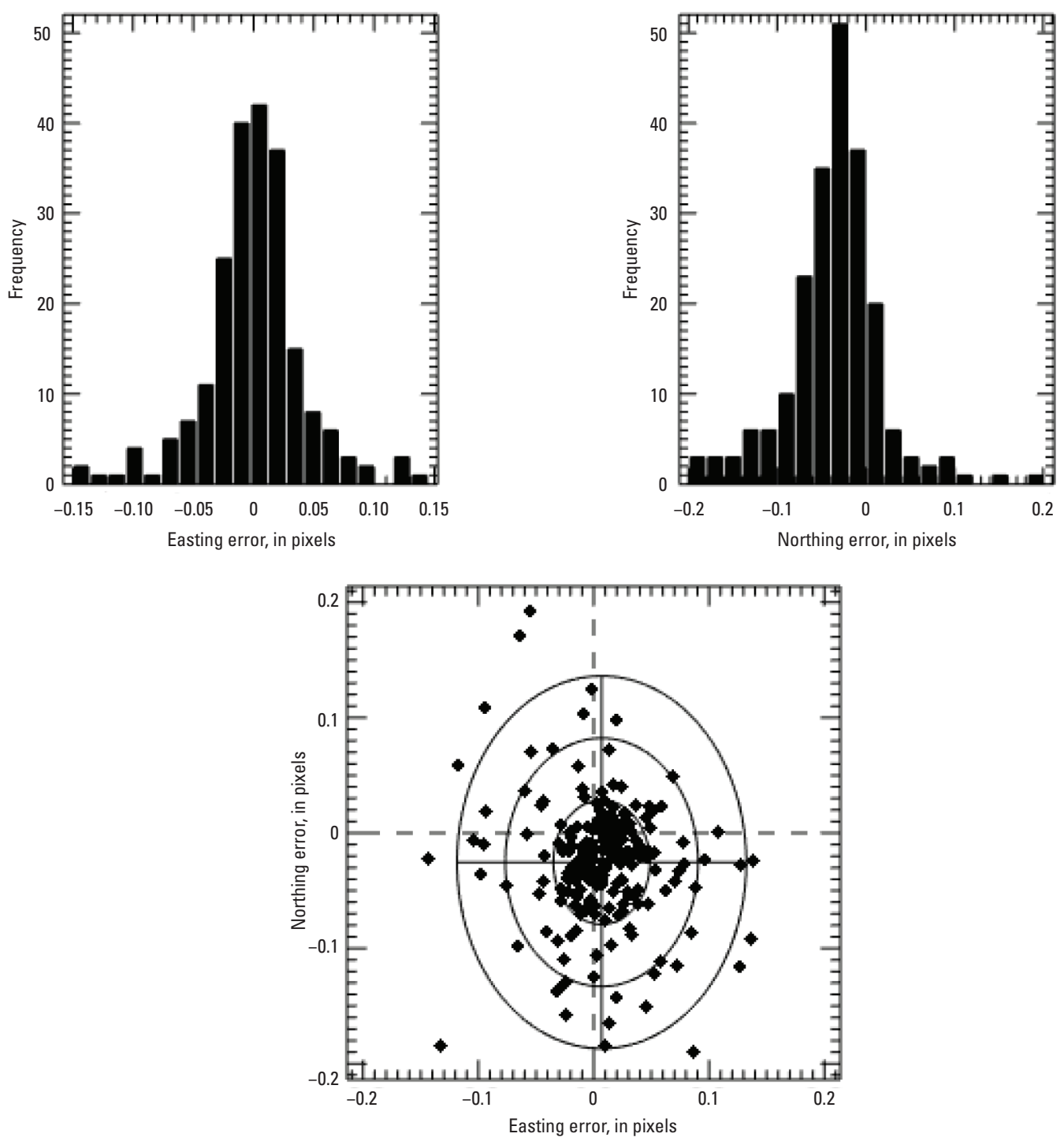

Figure 3. Band 1 (blue) to band 2 (green) geometric error histograms for easting and northing (upper) and error distribution (lower) for Roswell, New Mexico. 


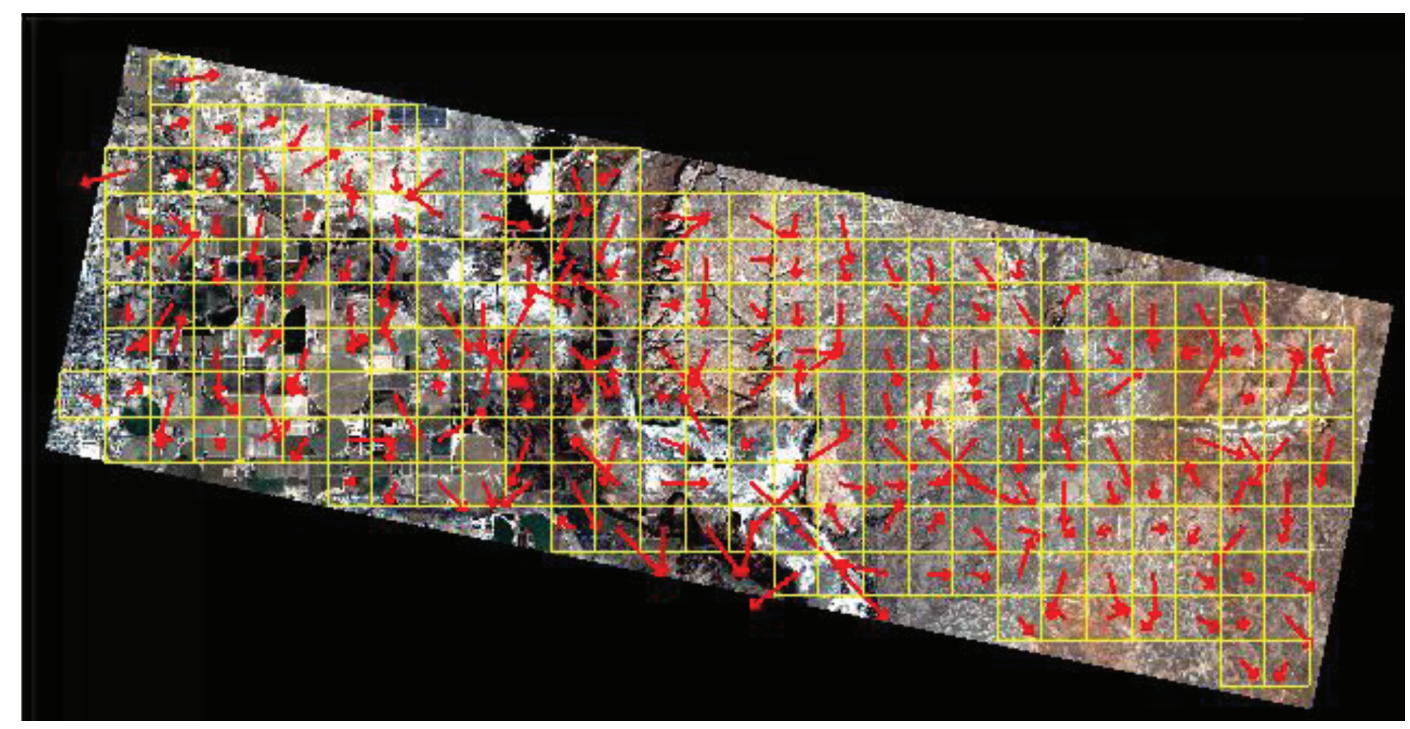

EXPLANATION

$\rightarrow$ Easting and northing error Grid

Figure 4. Band 2 (green) to band 3 (red) geometric error map of Roswell, New Mexico. 

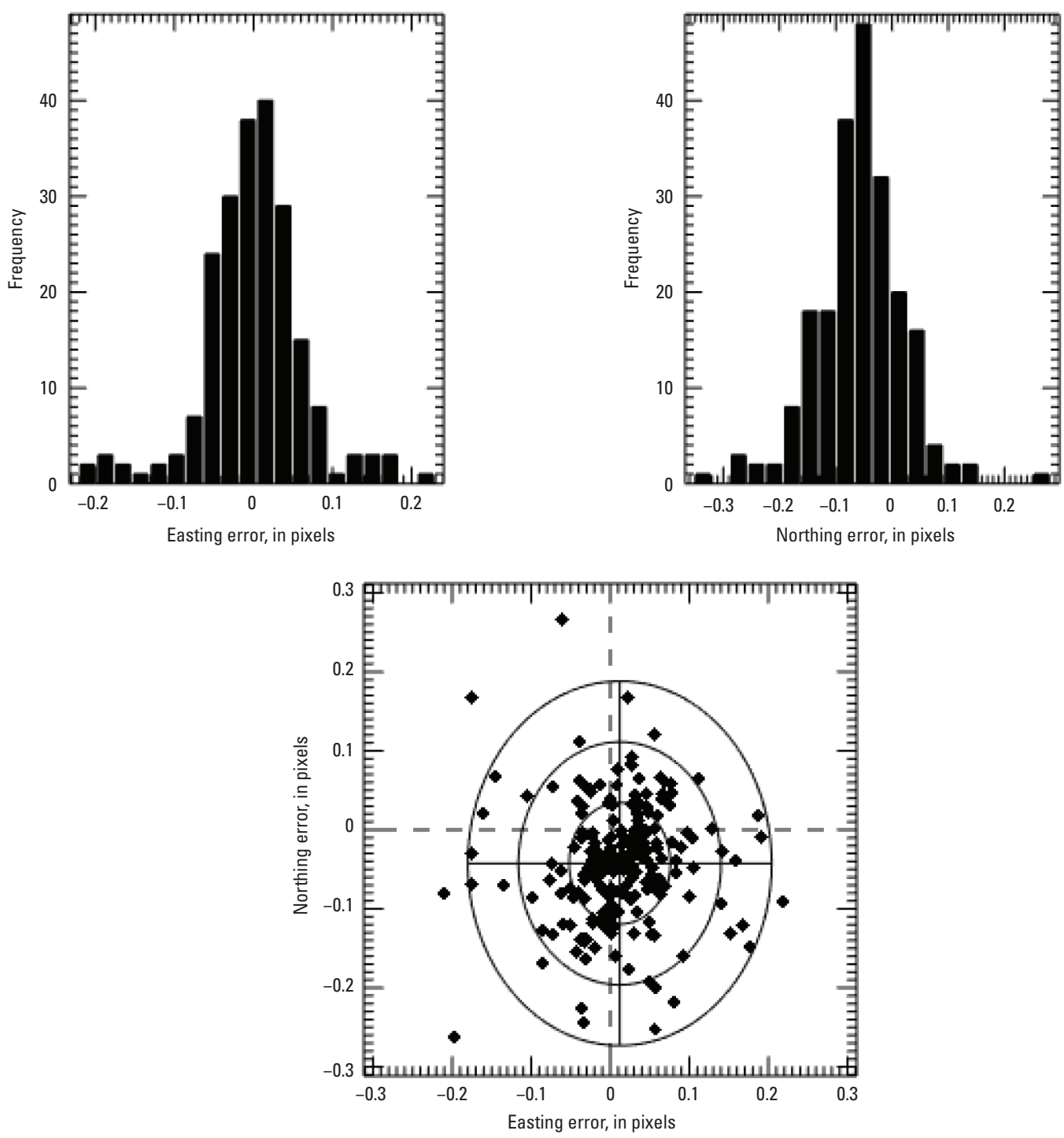

Figure 5. Band 2 (green) to band 3 (red) geometric error histograms for easting and northing (upper) and error distribution (lower) for Roswell, New Mexico. 


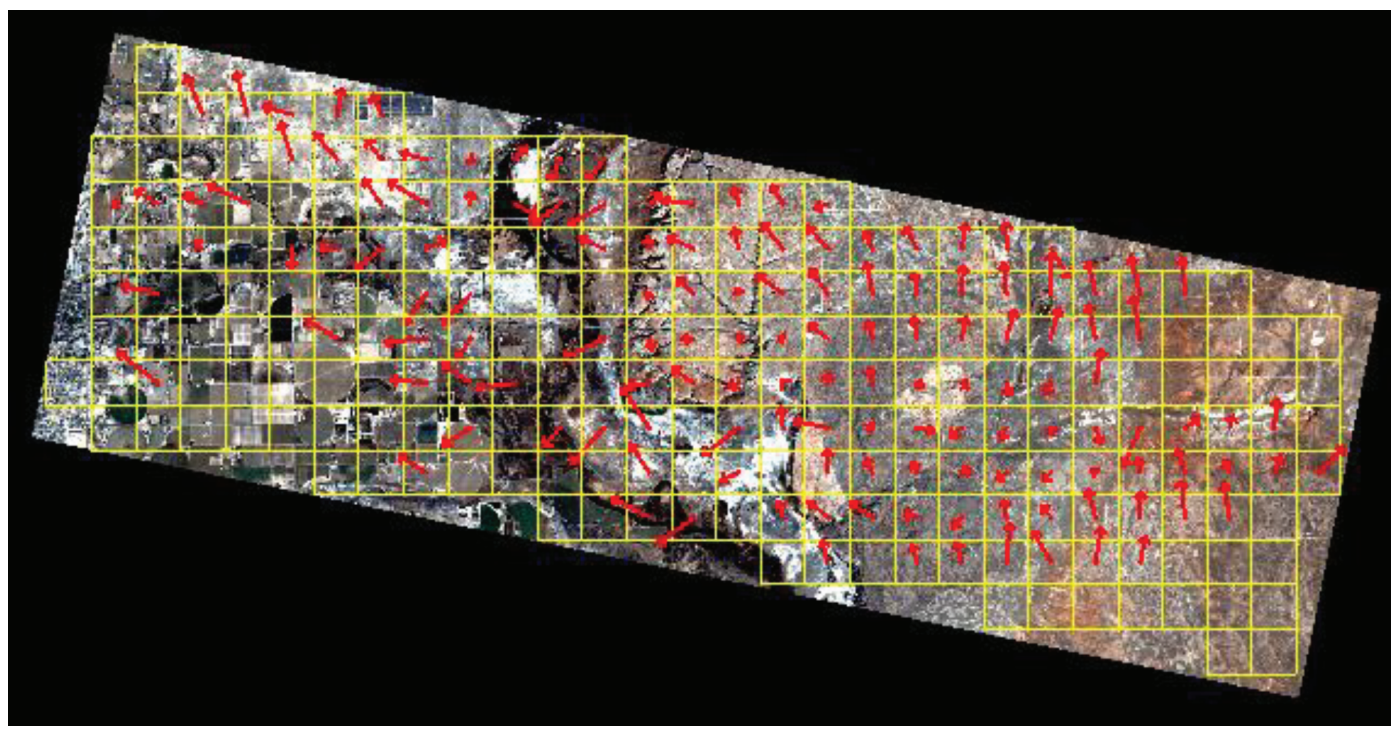

EXPLANATION

$\rightarrow$ Easting and northing error

Grid

Figure 6. Band 3 (red) to band 4 (near infrared) geometric error map of Roswell, New Mexico. 

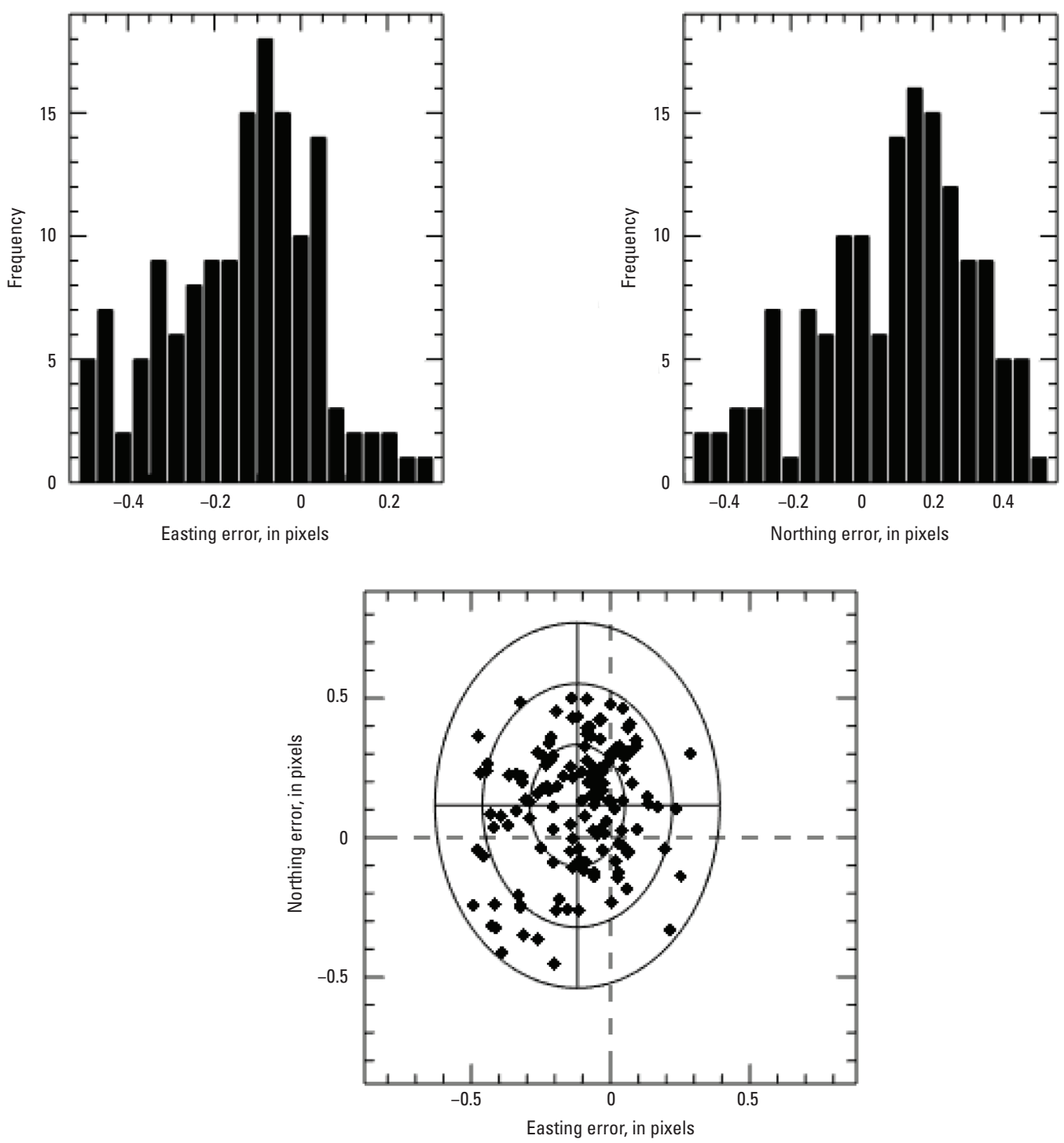

Figure 7. Band 3 (red) to band 4 (near infrared) geometric error histograms for easting and northing (upper) and error distribution (lower) for Roswell, New Mexico.

Table 5. Geometric error of Planet's Dove Classic imagery relative to Landsat 8 Operational Land Imager.

[RMSE, root mean square error; $m$, meter]

\begin{tabular}{|c|c|c|c|}
\hline Mean error (easting) & Mean error (northing) & RMSE (easting) & RMSE (northing) \\
\hline-2.280 pixels & -2.0781 pixels & 2.310 pixels & 2.187 pixels \\
\hline$(-6.841 \mathrm{~m})$ & $(-6.235 \mathrm{~m})$ & $(6.930 \mathrm{~m})$ & $(6.561 \mathrm{~m})$ \\
\hline
\end{tabular}




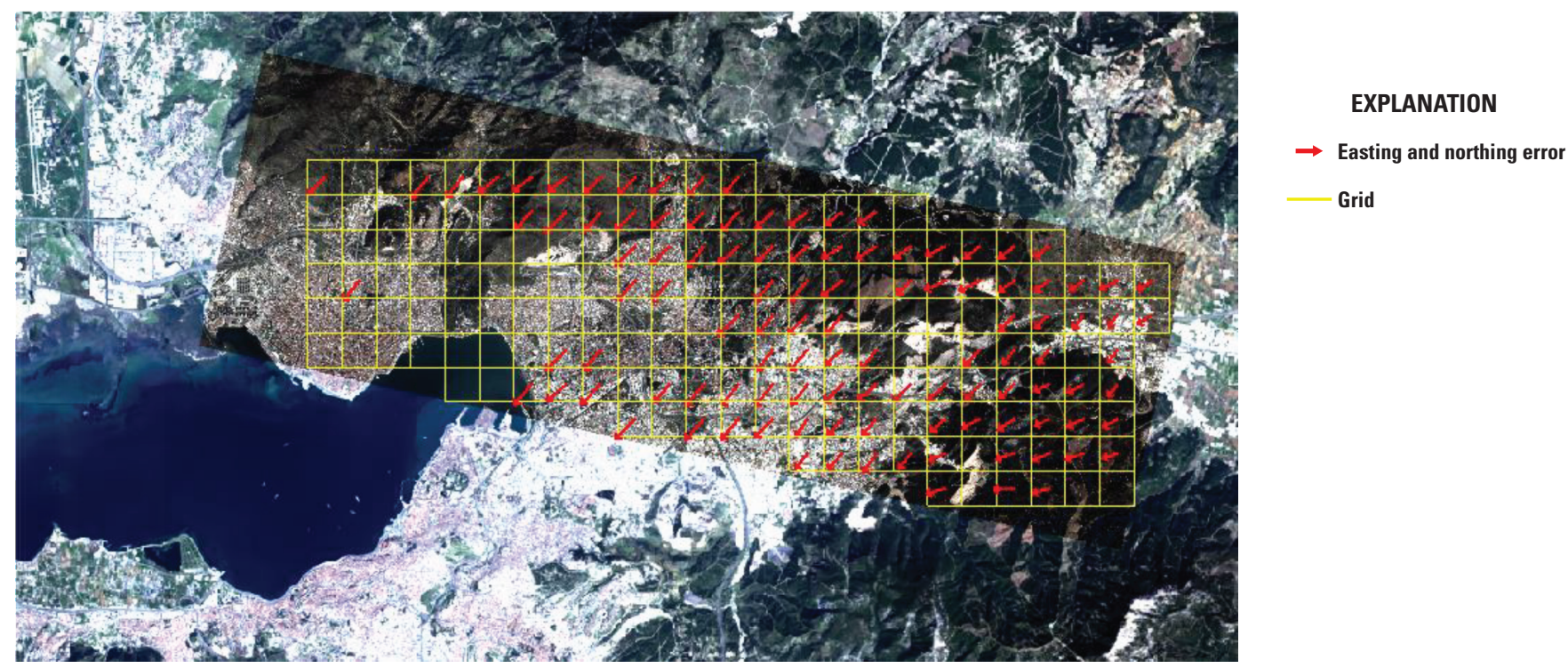

Figure 8. Relative geometric error map for Landsat 8 Operational Land Imager and Planet's Dove Classic for Izmir, Turkey. 

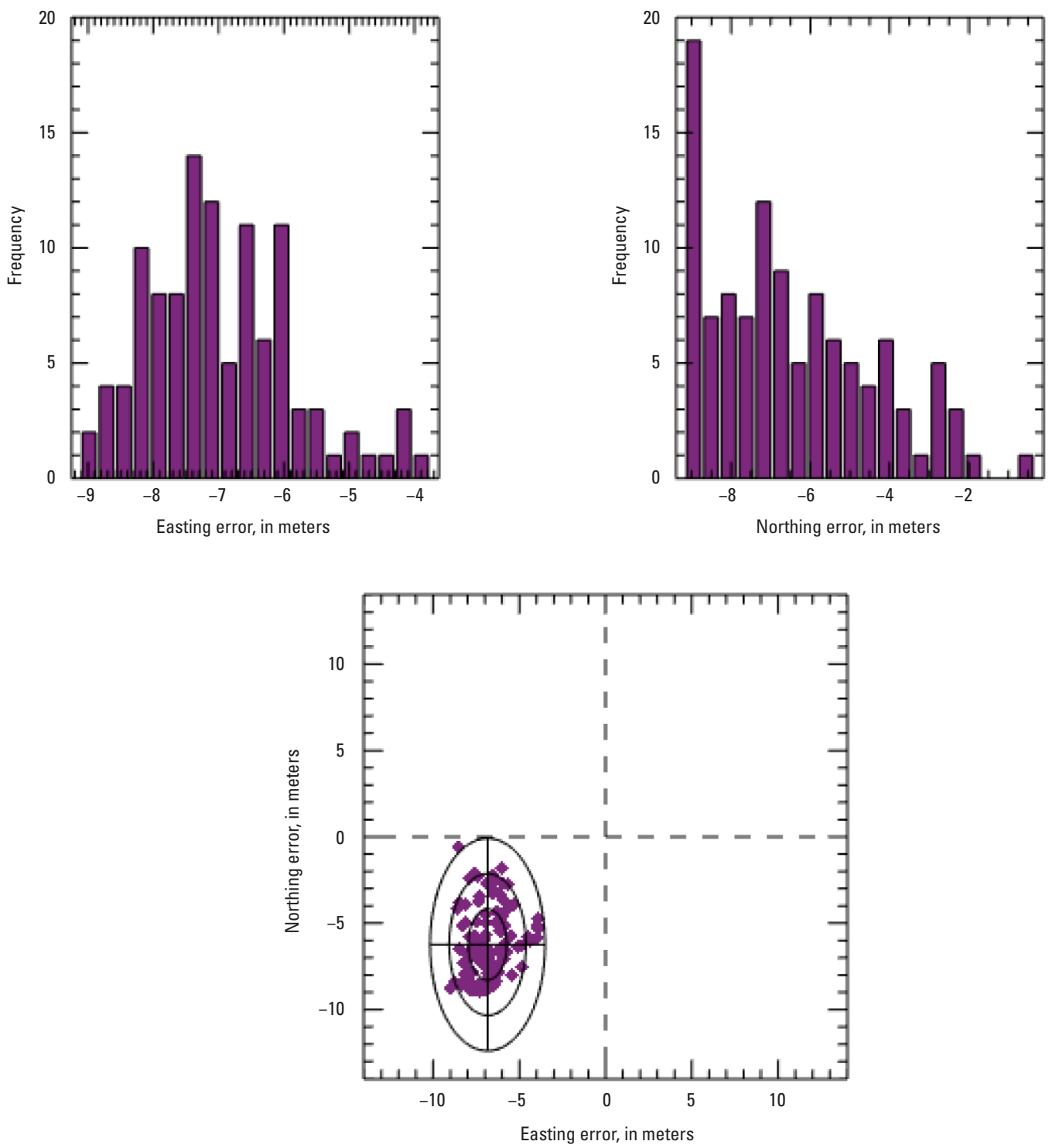

Figure 9. Relative geometric error histograms for easting and northing (upper) and error distribution (lower) for Izmir, Turkey.

Table 6. Top of Atmosphere reflectance comparison of Landsat 8 Operational Land Imager images against Planet's Dove Classic images.

[NIR, near infrared; $\sim$, about]

\begin{tabular}{lcccc}
\hline \multicolumn{1}{c}{ Statistics } & Band 1-Blue & Band 2-Green & Band 3-Red & Band 4-NIR \\
\hline Radical offset & -0.021 to 0.000 & -0.043 to $\sim 0.015$ & -0.062 to -0.019 & -0.103 to -0.025 \\
Radical slope & 0.991 to 1.114 & 1.081 to 1.224 & 1.177 to 1.409 & 1.282 to 1.500 \\
\hline
\end{tabular}




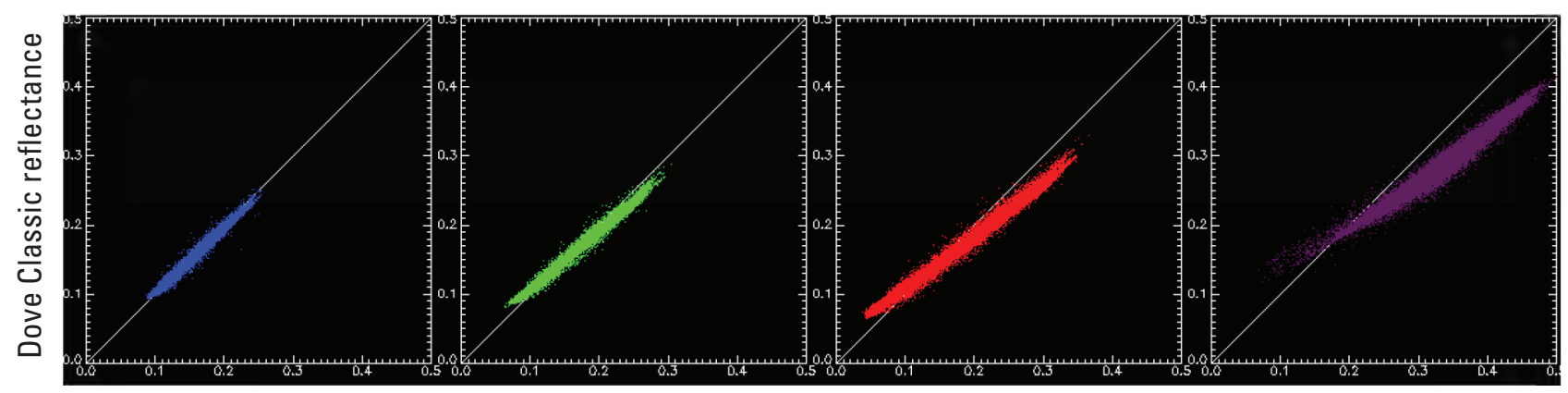

OLI reflectance (blue, green, red, near infrared)

Figure 10. Top of Atmosphere reflectance comparison for Landsat 8 Operational Land Imager (OLI) and Dove Classic, April 2017 scene pair (LC08_L1TP_023037_20170408_20170414_01_T1 and 20170408_160456_0e2f_3B_AnalyticMS, respectively).

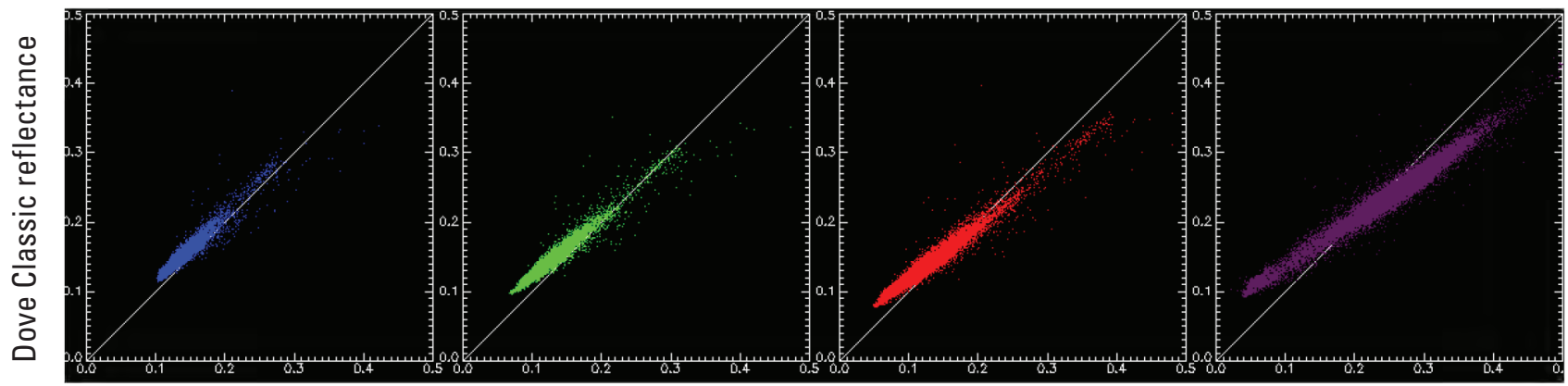

OLI reflectance (blue, green, red, near infrared)

Figure 11. Top of Atmosphere reflectance comparison for Landsat 8 Operational Land Imager (OLI) and Dove Classic, December 2017 scene pair (LC08_L1TP_128049_20171220_20171224_01_T1 and 20171220_030332_0e2f_3B_AnalyticMS, respectively).

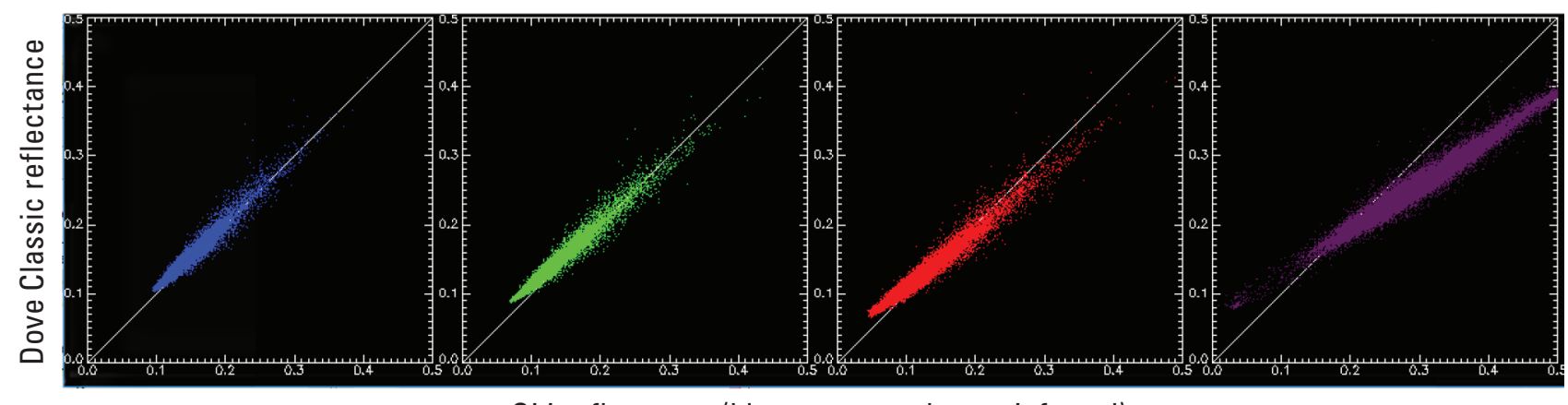

OLI reflectance (blue, green, red, near infrared)

Figure 12. Top of Atmosphere reflectance comparison for Landsat 8 Operational Land Imager (OLI) and Dove Classic, August 2018 scene pair (LC08_L1TP_192029_20180817_20180829_01_T1 and 20180817_093542_0e2f_3B_AnalyticMS, respectively). 


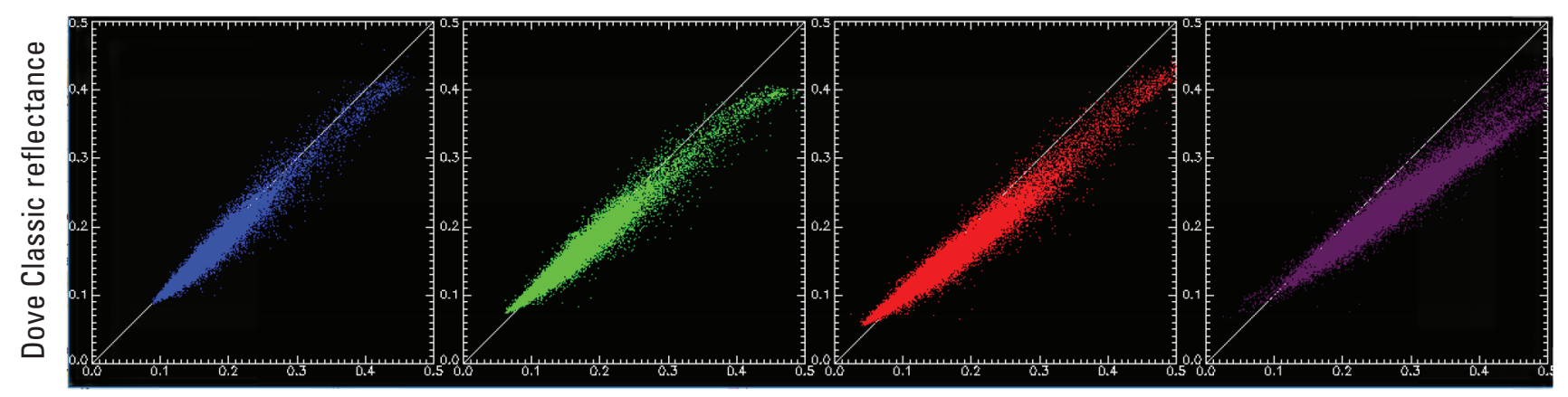

OLI reflectance (blue, green, red, near infrared)

Figure 13. Top of Atmosphere reflectance comparison for Landsat 8 Operational Land Imager (OLI) and Dove Classic, March 2019 scene pair (LC08_L1TP_180032_20190325_20190403_01_T1 and 20190325_082920_0e2f_3B_AnalyticMS, respectively).

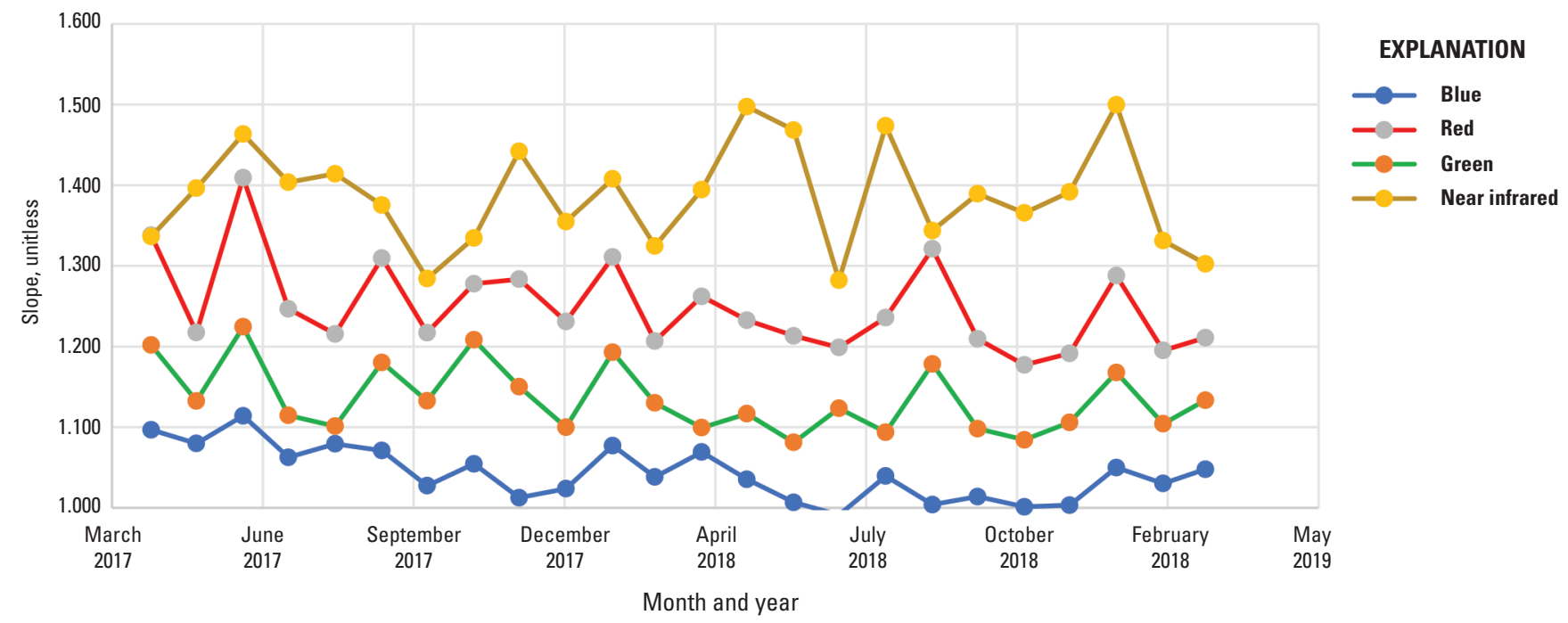

Figure 14. Time series of Landsat 8 Operational Land Imager and Planet's Dove Classic radiometric slope comparison.

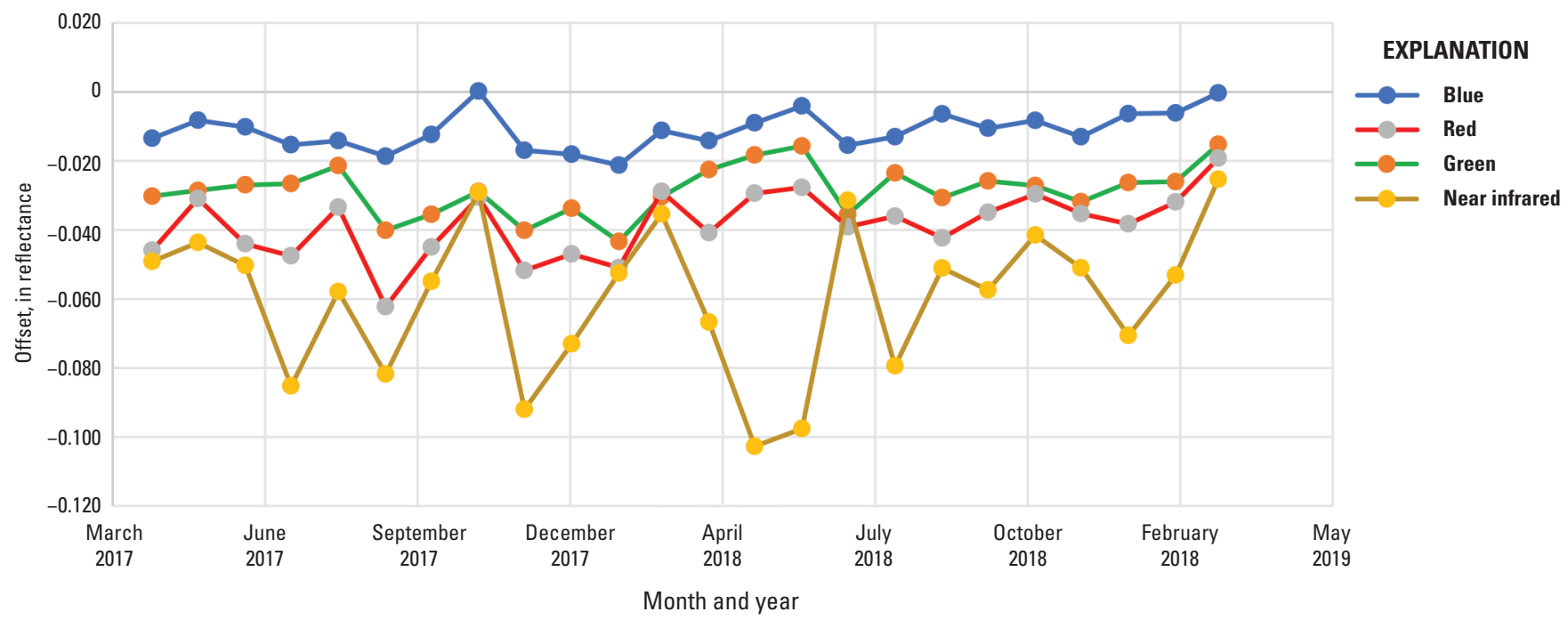

Figure 15. Time series of Landsat 8 Operational Land Imager and Planet's Dove Classic radiometric offset comparison. 
Table 7. Spatial performance of Planet's Dove Classic.

[RER, relative edge response; FWMH, full width at half maximum; MTF, modulation transfer function; NIR, near infrared]

\begin{tabular}{lccc}
\hline \multicolumn{1}{c}{ Spatial analysis } & RER & FWHM & MTF at Nyquist \\
\hline Band 1-blue & 0.36 & 2.77 pixels & 0.010 \\
Band 2-green & 0.33 & 3.07 pixels & 0.003 \\
Band 3-red & 0.33 & 3.07 pixels & 0.007 \\
Band 4-NIR & 0.27 & 3.35 pixels & 0.006 \\
\hline
\end{tabular}

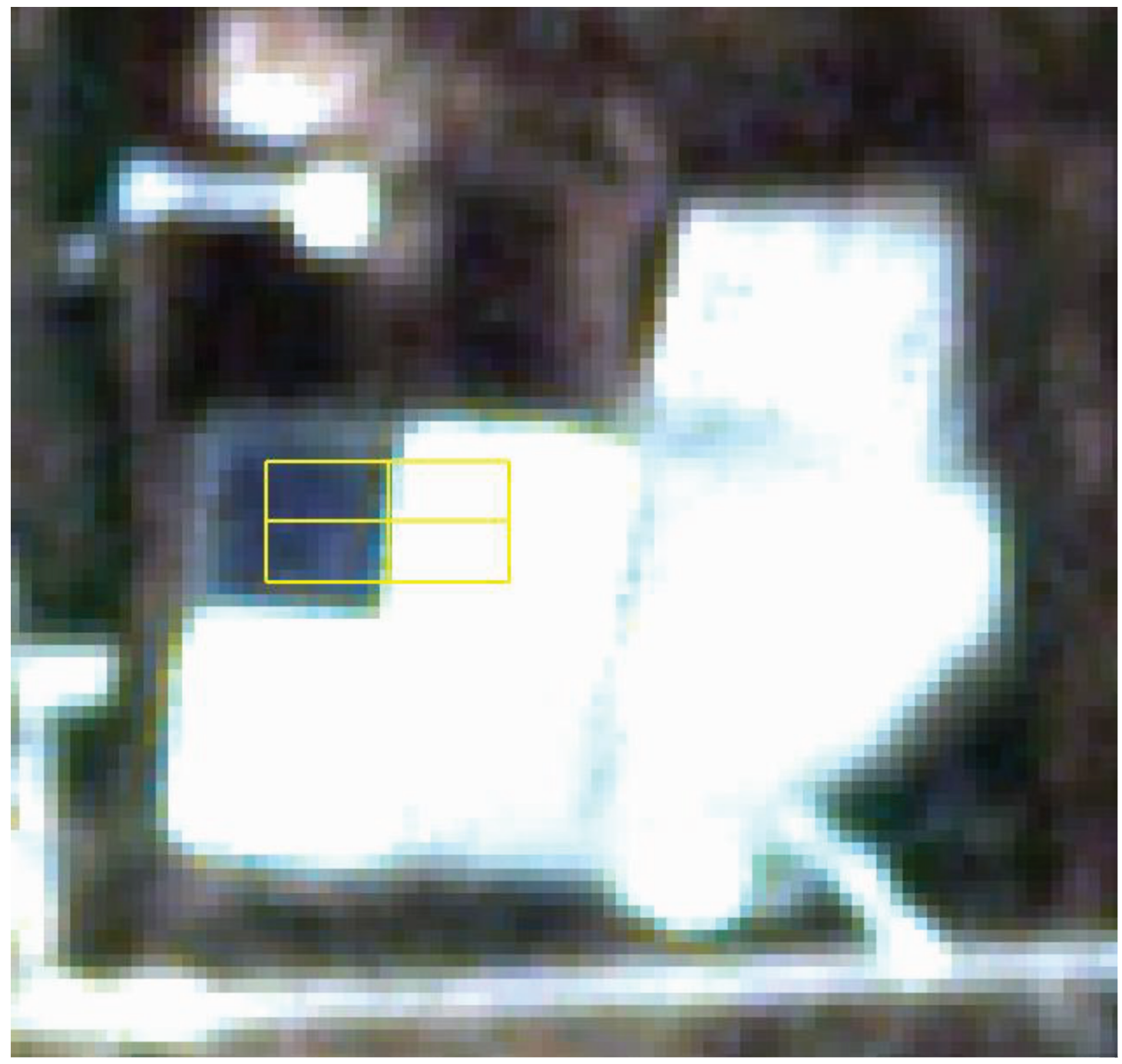

\section{EXPLANATION}

Grid showing the edge transect region of interest

Figure 16. Dove-Classic image of calibration site at Baotou, China. 


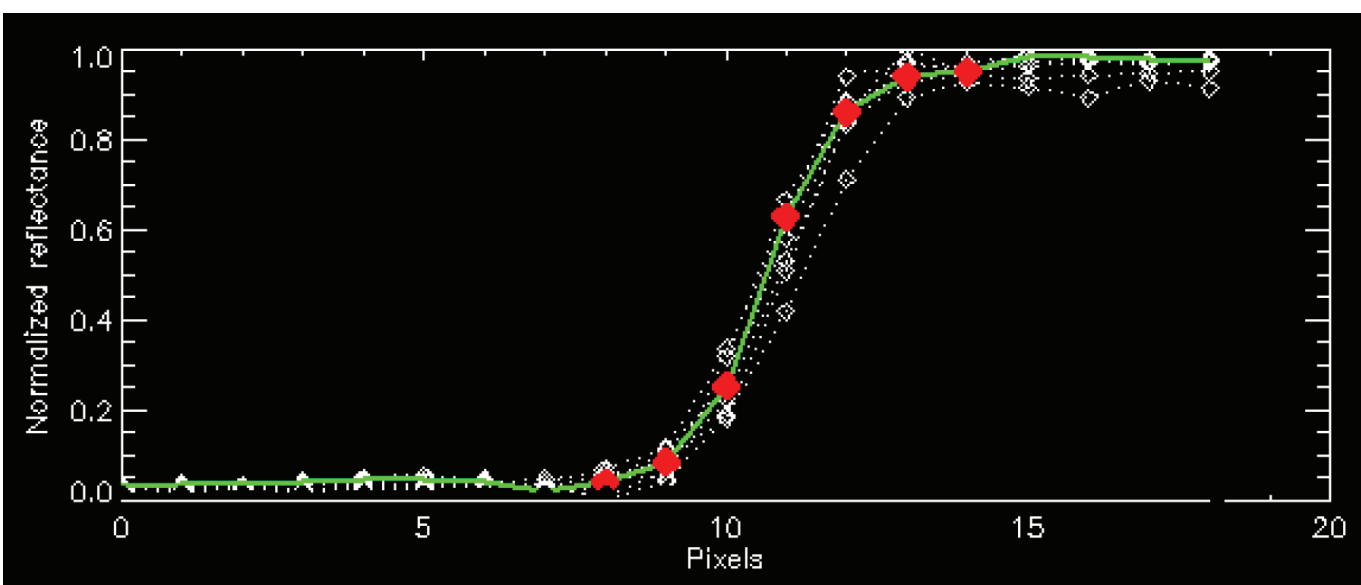

\section{EXPLANATION}

Discrete points used for alignment

.4 . Raw reflectance along the transect line

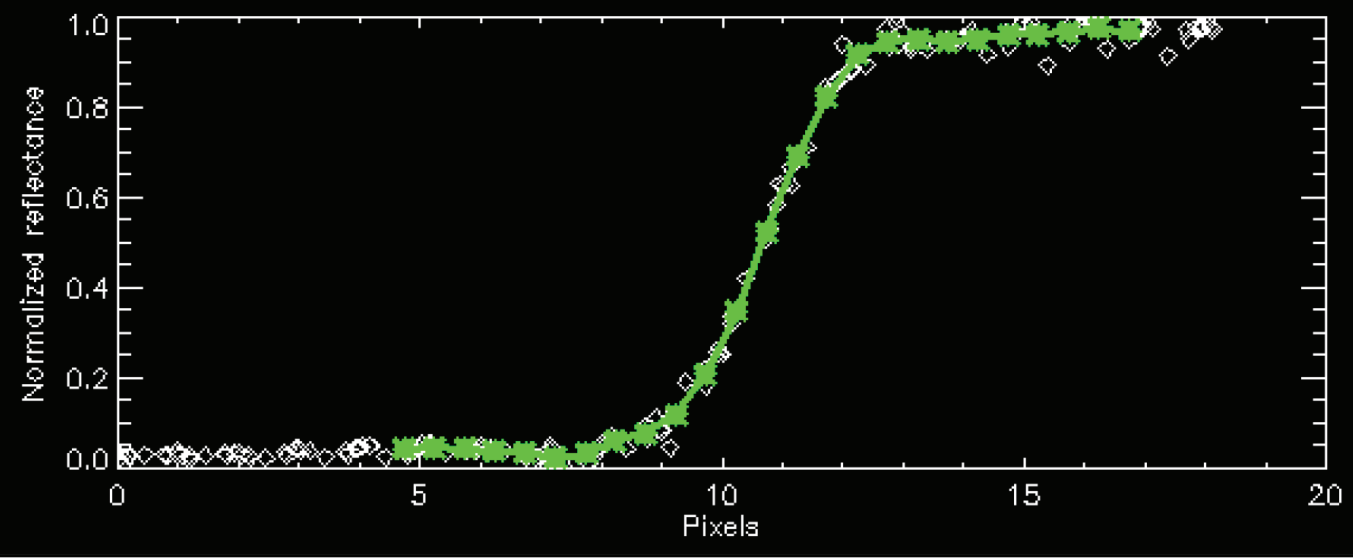

\section{EXPLANATION}

Central line out of all edge transect lines

Q Raw reflectance along the transect line

Figure 17. Band 1 (blue) raw edge transects (upper) and shifted transects (lower) for Baotou, China 


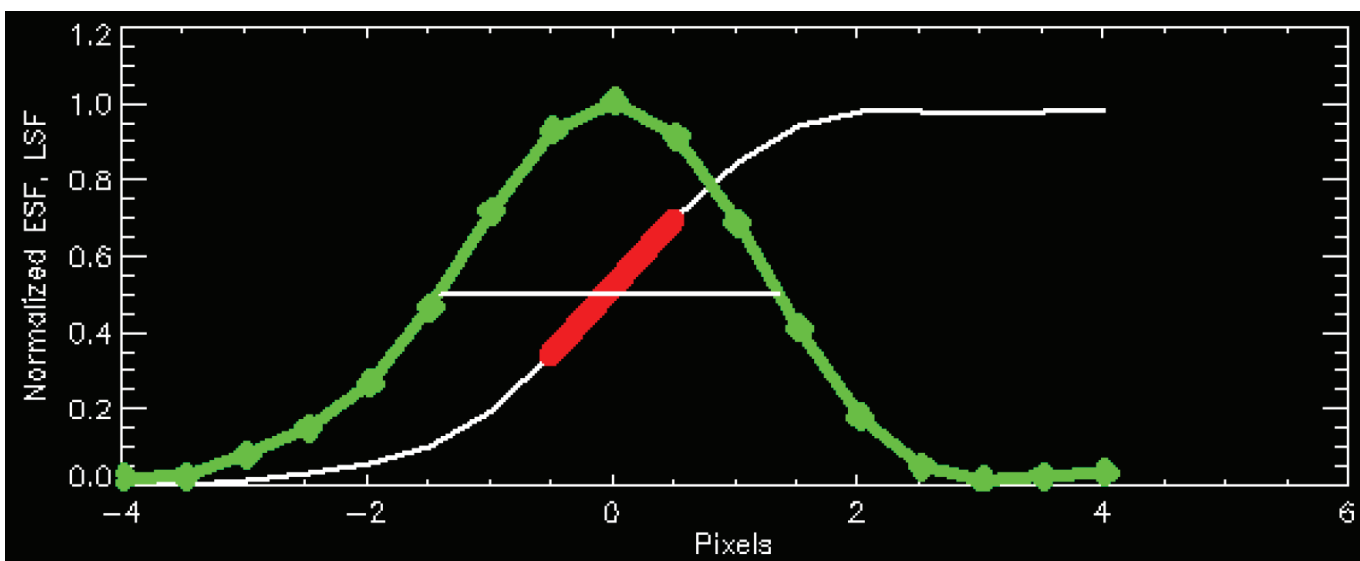

\section{EXPLANATION \\ Line spread function \\ Edge spread function}

\section{EXPLANATION}

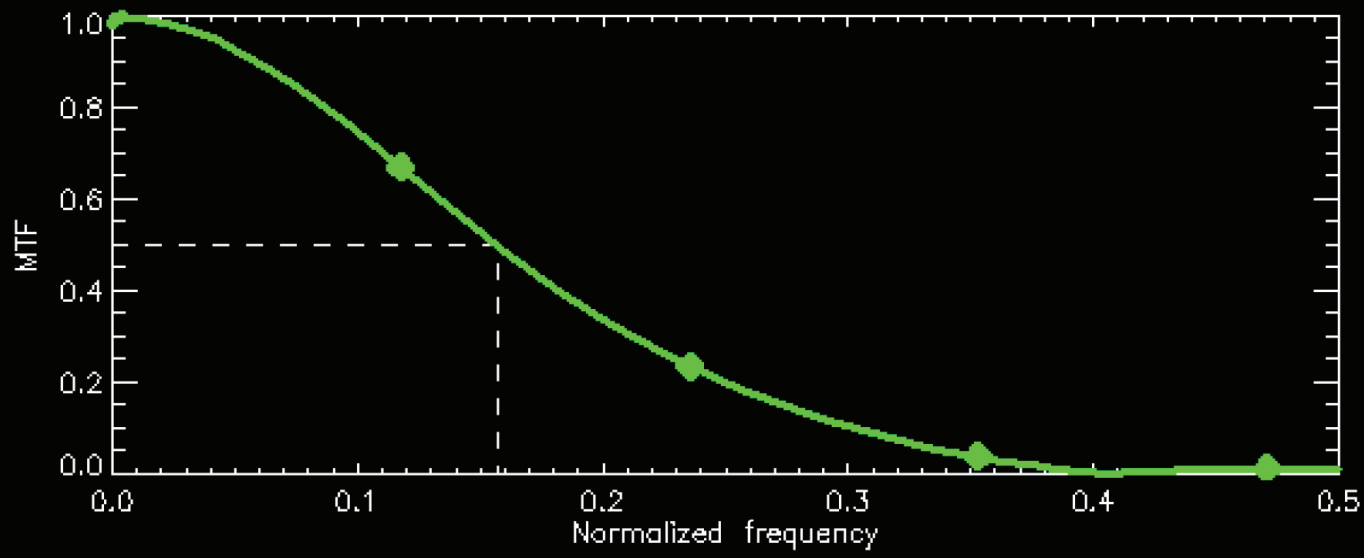

Modulation transfer function

- $-\quad x$ value at corresponding $y$ value

Figure 18. Band 1 (blue) edge spread function (ESF) and line spread function (LSF; upper) and modulation transfer function (MTF; lower) for Baotou, China. 


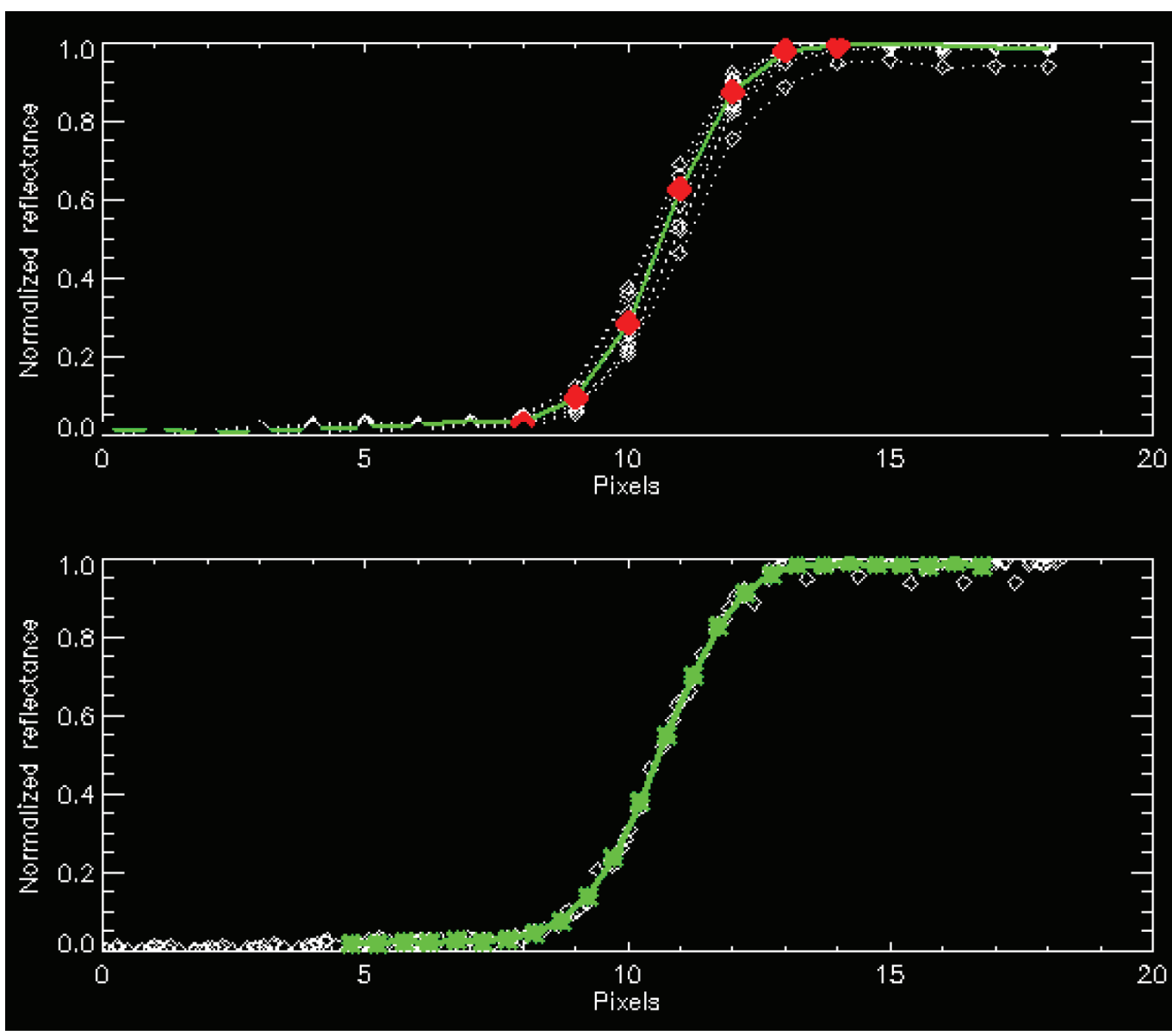

\section{EXPLANATION}

Discrete points used for alignment

Raw reflectance along the transect line

\section{EXPLANATION}

Central line out of all edge transect lines

$4 \quad$ Raw reflectance along the transect line

Figure 19. Band 2 (green) raw edge transects (upper) and shifted transects (lower) for Baotou, China. 

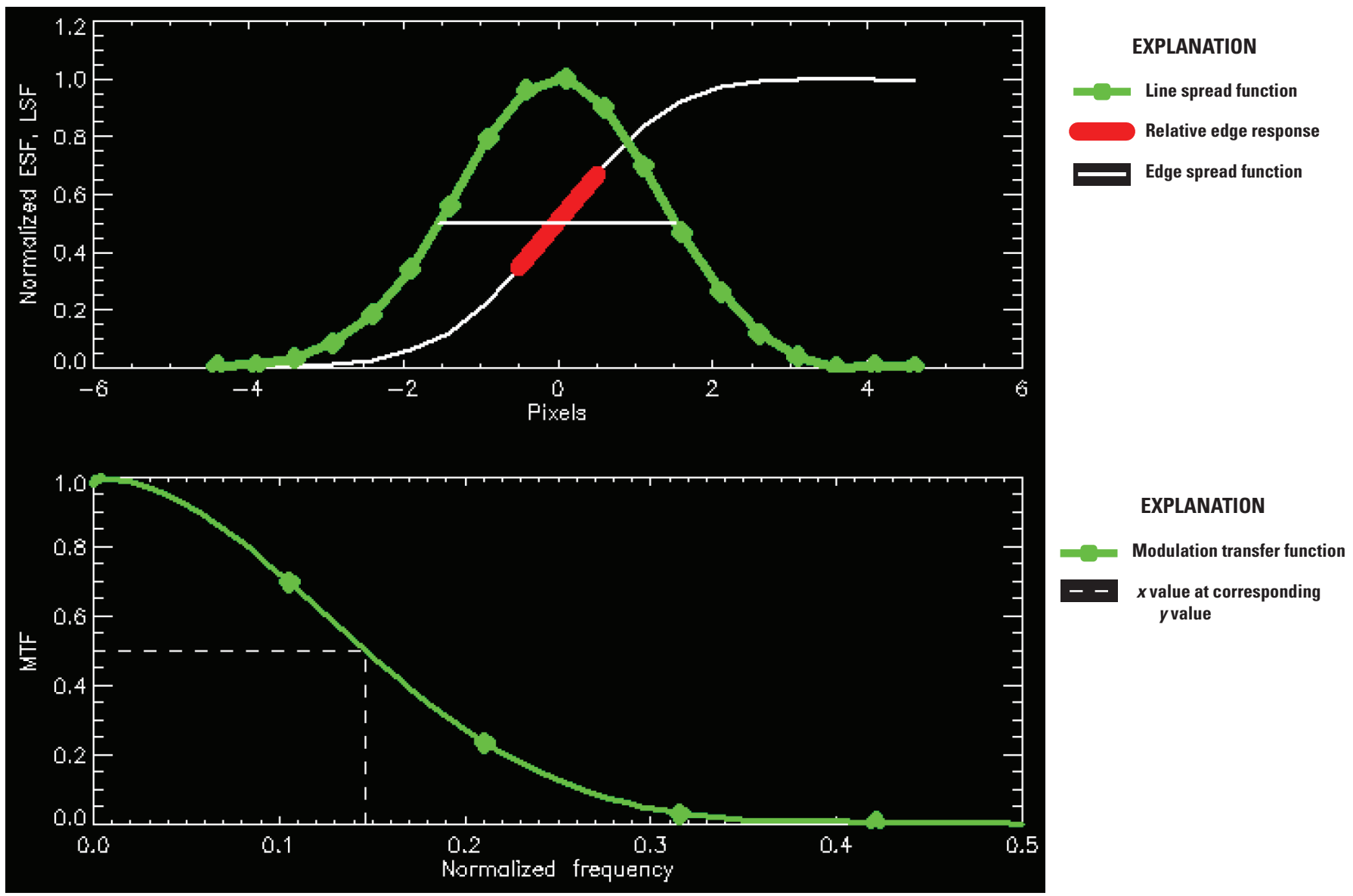

$y$ value

Figure 20. Band 2 (green) edge spread function (ESF) and line spread function (LSF; upper) and modulation transfer function (MTF; lower) for Baotou, China. 

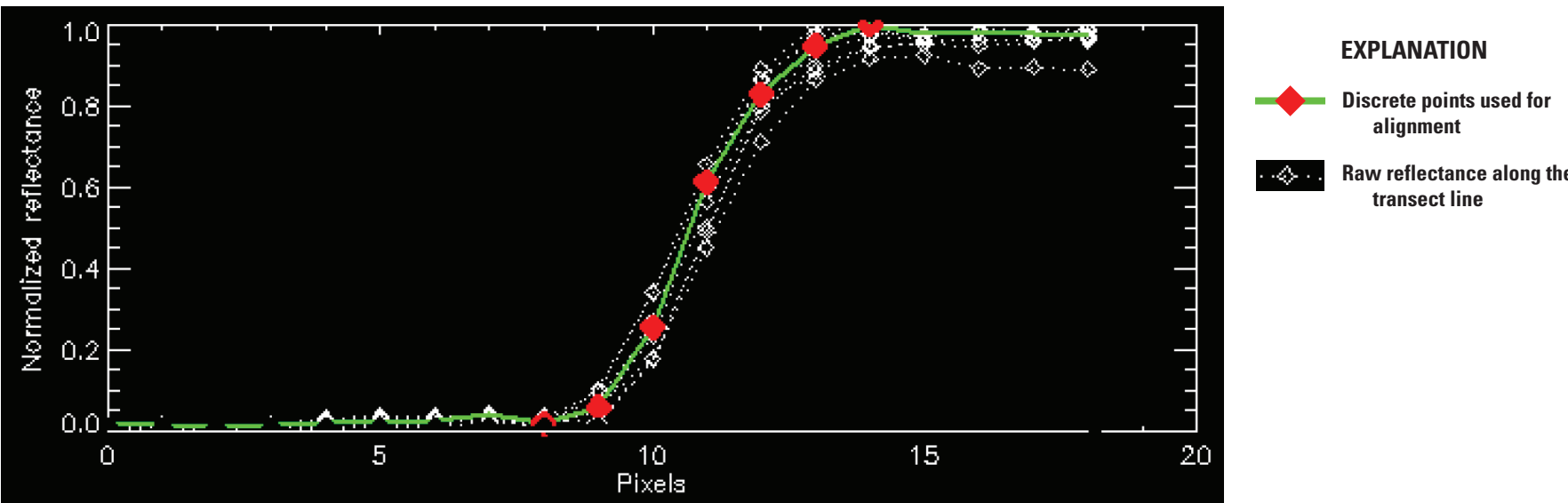

Raw reflectance along the transect line

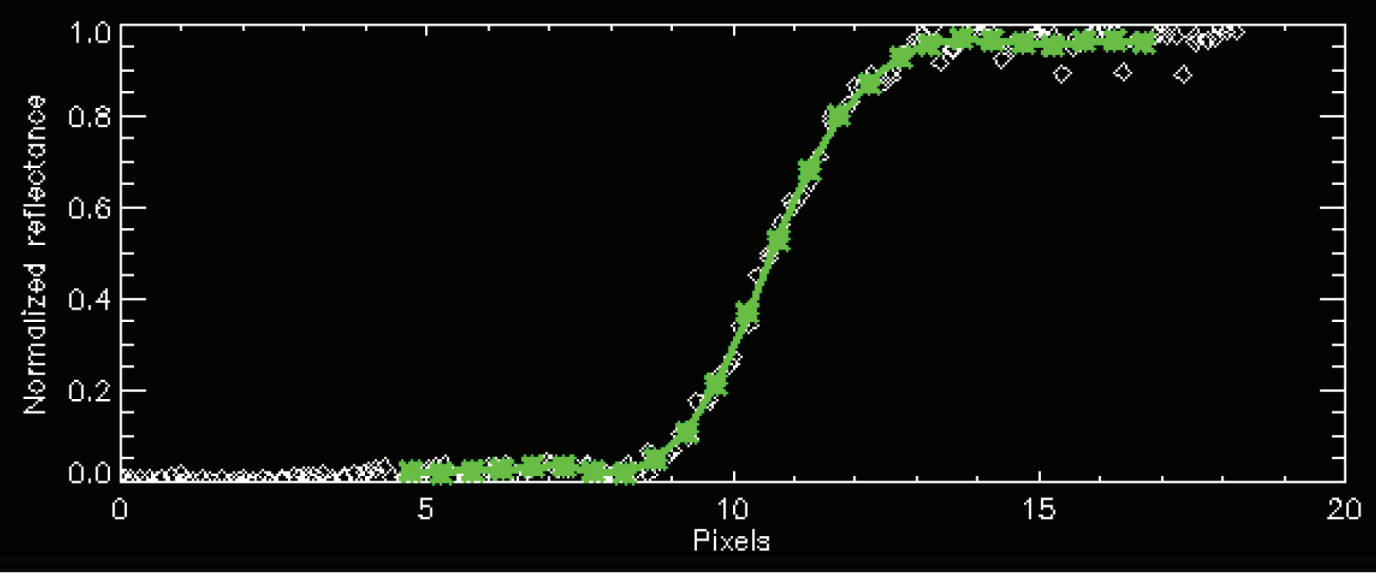

\section{EXPLANATION}

Central line out of all edge transect lines

4 Raw reflectance along the transect line

Figure 21. Band 3 (red) raw edge transects (upper) and shifted transects (lower) for Baotou, China. 


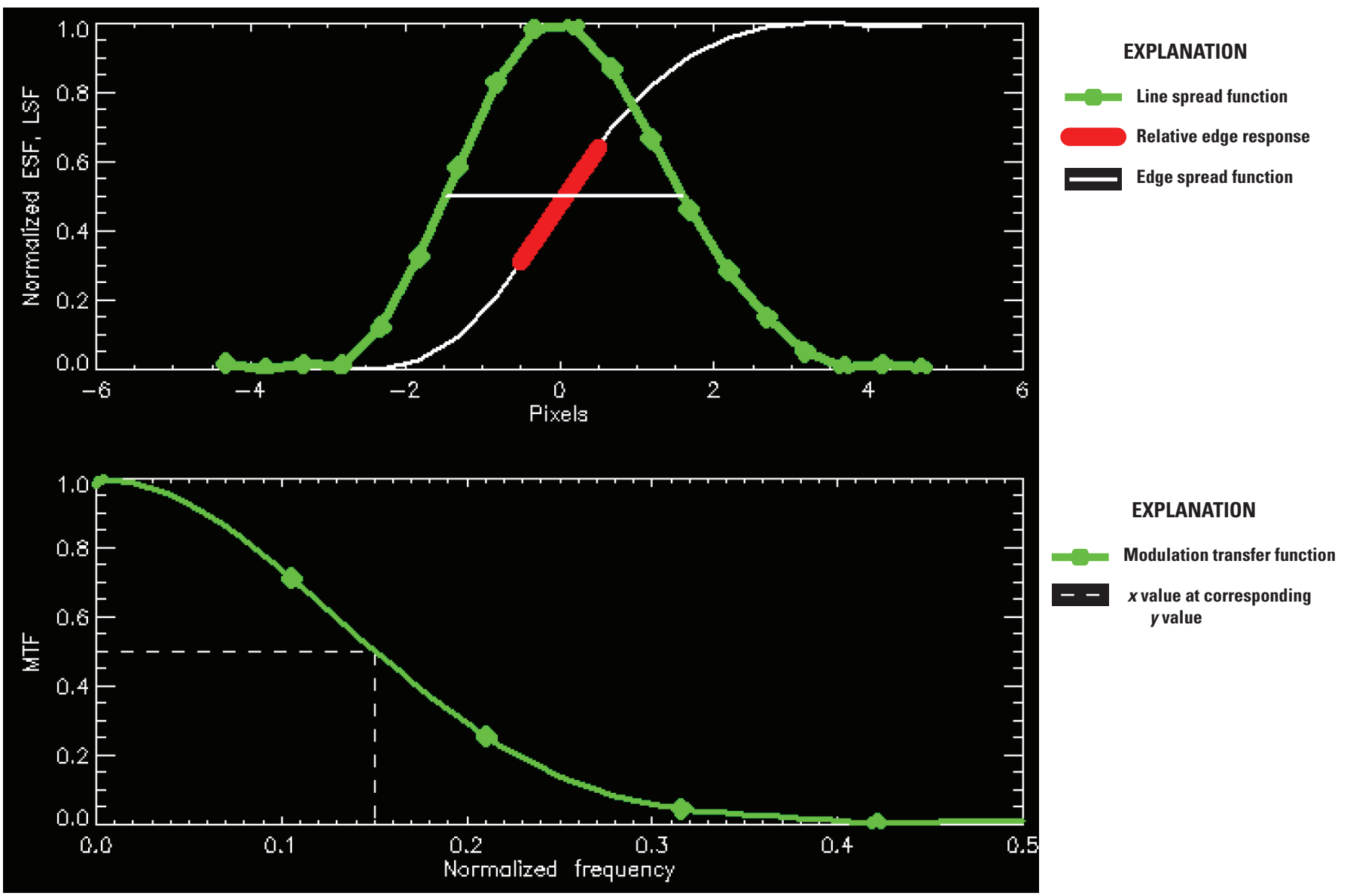

Figure 22. Band 3 (red) edge spread function (ESF) and line spread function (LSF; upper) and modulation transfer function (MTF; lower) for Baotou, China. 

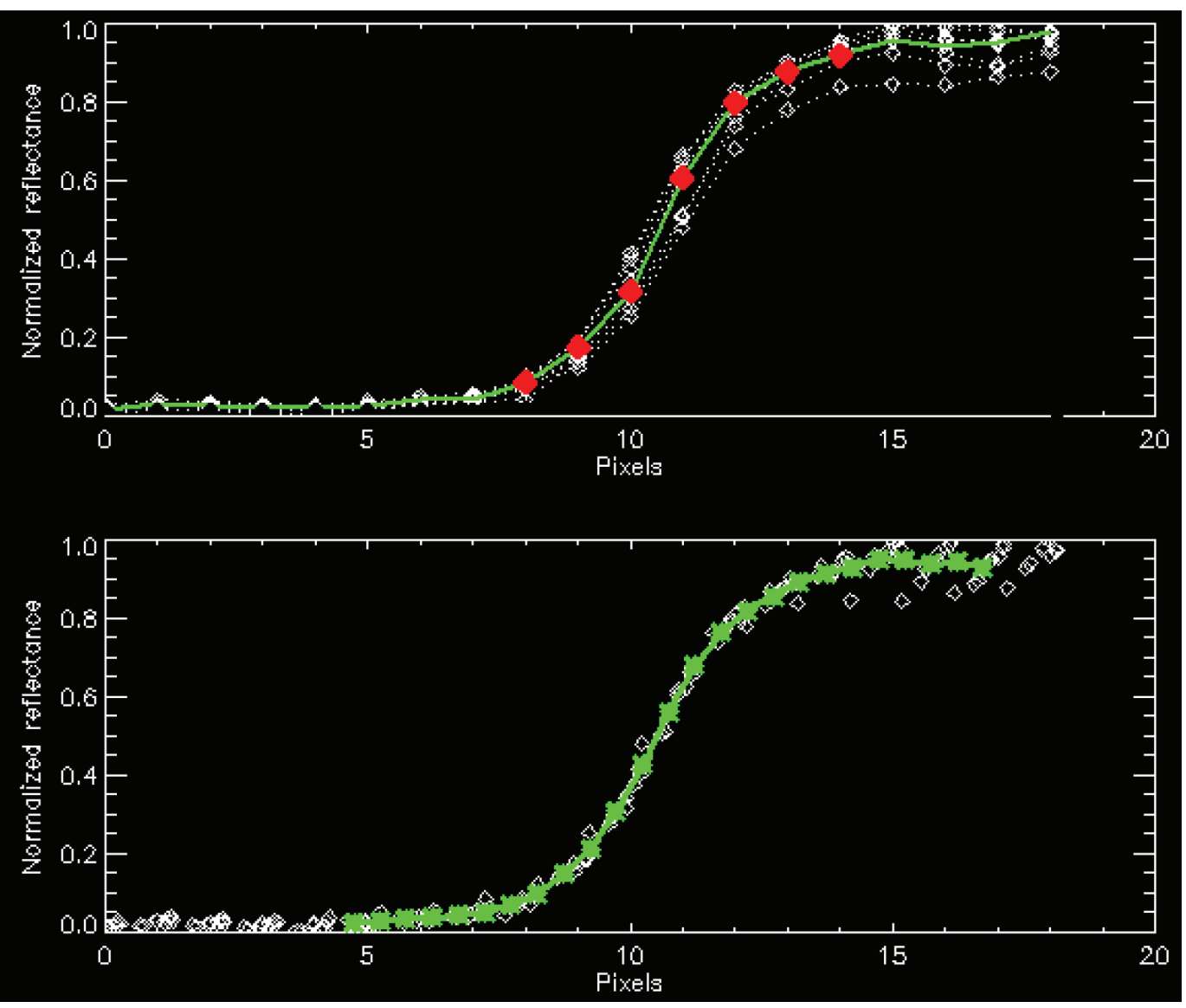

\section{EXPLANATION}

Central line out of all edge transect lines

Raw reflectance along the transect line

Figure 23. Band 4 (near infrared) raw edge transects (upper) and shifted transects (lower) for Baotou, China. 


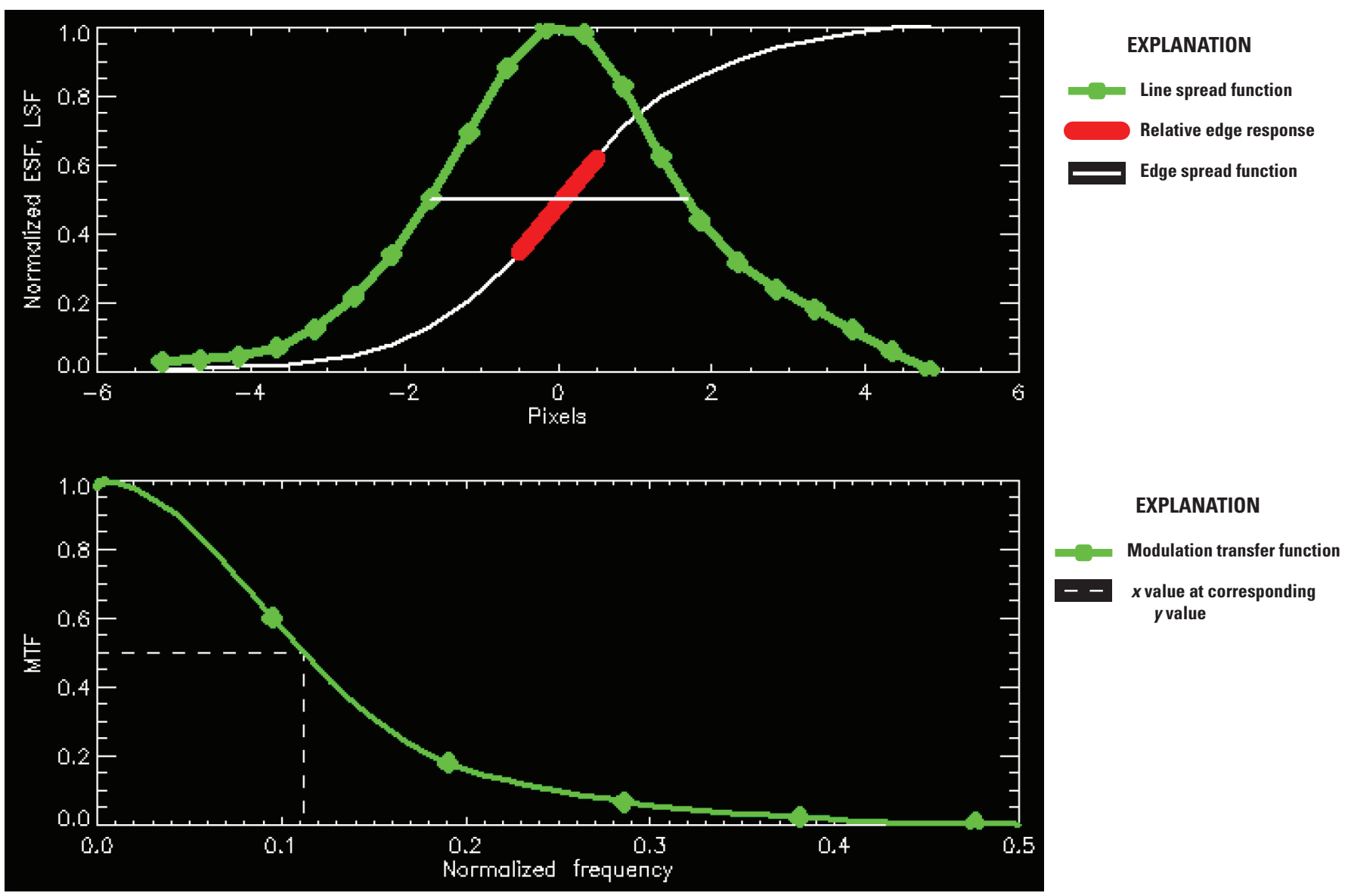

Figure 24. Band 4 (near infrared) edge spread function (ESF) and line spread function (LSF; upper) and modulation transfer function (MTF; lower) for Baotou, China.

\section{Summary and Conclusions}

This report summarizes the sensor performance of Planet's Dove Classic system based on the U.S. Geological Survey Earth Resources Observation and Science Cal/Val Center of Excellence (ECCOE) system characterization process. In summary, we have determined that this sensor provides an interior geometric performance in the range of -0.218 $(-0.073$ pixel $)$ to -0.037 meter $(\mathrm{m} ;-0.012$ pixel $)$ in easting -0.167 ( -0.056 pixel) to $-0.111 \mathrm{~m}(-0.037$ pixel) in northing in band-to-band registration, an exterior geometric error of -6.841 ( -2.280 pixels) in easting $-6.235 \mathrm{~m}(-2.078$ pixels $)$ in northing offset in comparison to Landsat 8 OLI, a radiometric performance in the range of -0.057 to -0.010 in offset and 0.963 to 1.298 in slope, and a spatial performance in the range of 2.77 to 3.35 pixels for full width at half maximum, with a modulation transfer function at a Nyquist frequency in the range of 0.003 to 0.010 .
In conclusion, the team has completed an ECCOE standardized system characterization of the Dove Classic sensing system. Although the team followed characterization procedures that are standardized across the many sensors and sensing systems under evaluation, these procedures are customized to fit the individual sensor as was done with Dove Classic. The team has acquired the data, defined proper testing methodologies, carried out comparative tests against specific references, recorded measurements, completed data analyses, and quantified sensor performance accordingly. The team also endeavored to retain all data, measurements, and methods. This is key to ensure that all data and measurements are archived and accessible and that the performance results are reproducible.

The ECCOE project and associated Joint Agency Commercial Imagery Evaluation partners are always interested in reviewing sensor and remote sensing application assessments and would like to see and discuss information on similar data and product assessments and reviews. If you would like to discuss system characterization with the U.S. Geological Survey ECCOE and (or) the Joint Agency Commercial Imagery Evaluation team, please email us at eccoe@usgs.gov. 


\section{Selected References}

Planet Labs, Inc., 2021, Planet: Planet Labs, Inc., web page, accessed May 10, 2020, at https:/www.planet.com/.

Ramaseri Chandra, S.N., Christopherson, J.B., and Casey, K.A., 2020, 2020 Joint Agency Commercial Imagery Evaluation-Remote sensing satellite compendium: U.S. Geological Survey Circular 1468 (ver. 1.1, October 2020), 253 p. [Also available at https://doi.org/10.3133/cir1468.] [Supersedes USGS Circular 1455.]
U.S. Geological Survey, 2020a, EROS CalVal Center of Excellence (ECCOE): U.S. Geological Survey web page, accessed May 10, 2020, at https://www.usgs.gov/corescience-systems/eros/calval.

U.S. Geological Survey, 2020b, Landsat missions-Glossary and acronyms: U.S. Geological Survey web page, accessed May 10, 2020, at https://www.usgs.gov/core-sciencesystems/nli/landsat/glossary-and-acronyms. 


\section{Appendix 1. Radiometric Data}

Datasets used for the radiometric stability time-series analysis are listed in table 1.1. 
Table 1.1. Radiometric time-series analysis reference datasets.

[OLI, Operational Land Imager; ID, identifier;_02ef, camera identifier; m, meter]

\begin{tabular}{|c|c|c|c|}
\hline Month & Landsat 8 OLI product ID & Dove Classic ID (_02ef) & Time difference (m) \\
\hline Apr. 2017 & LC08_L1TP_023037_20170408_20170414_01_T1 & 20170408_160456 & 33 \\
\hline Apr. 2017 & LC08_L1TP_023037_20170408_20170414_01_T1 & 20170408_160504 & 33 \\
\hline May 2017 & LC08_L1TP_089084_20170524_20170614_01_T1 & 20170524_231640 & 26 \\
\hline May 2017 & LC08_L1TP_089084_20170524_20170614_01_T1 & 20170524_231641 & 26 \\
\hline May 2017 & LC08_L1TP_089084_20170524_20170614_01_T1 & 20170524_231642 & 26 \\
\hline June 2017 & LC08_L1TP_033042_20170601_20170615_01_T1 & 20170601_171146 & 29 \\
\hline June 2017 & LC08_L1TP_033042_20170601_20170615_01_T1 & 20170601_171147 & 29 \\
\hline June 2017 & LC08_L1TP_033042_20170601_20170615_01_T1 & 20170601_171148 & 29 \\
\hline July 2017 & LC08_L1TP_036029_20170708_20170717_01_T1 & 20170725_172115 & 32 \\
\hline July 2017 & LC08_L1TP_036037_20170708_20170717_01_T1 & 20170725_172420 & 33 \\
\hline July 2017 & LC08_L1TP_036037_20170708_20170717_01_T1 & 20170725_172421 & 33 \\
\hline Aug. 2017 & LC08_L1TP_178034_20170828_20170914_01_T1 & 20170828_080308 & 30 \\
\hline Aug. 2017 & LC08_L1TP_178034_20170828_20170914_01_T1 & 20170828_080309 & 30 \\
\hline Sept. 2017 & LC08_L1TP_168035_20170923_20171013_01_T1 & 20170923_070407 & 29 \\
\hline Oct. 2017 & LC08_L1TP_168034_20171025_20171107_01_T1 & 20171025_070102 & 30 \\
\hline Oct. 2017 & LC08_L1TP_168034_20171025_20171107_01_T1 & 20171025_070107 & 30 \\
\hline Oct. 2017 & LC08_L1TP_168034_20171025_20171107_01_T1 & 20171025_070126 & 30 \\
\hline Nov. 2017 & LC08_L1TP_197035_20171121_20171206_01_T1 & 20171121_100852 & 24 \\
\hline Nov. 2017 & LC08_L1TP_197035_20171121_20171206_01_T1 & 20171121_100855 & 24 \\
\hline Nov. 2017 & LC08_L1TP_197035_20171121_20171206_01_T1 & 20171121_100857 & 24 \\
\hline Dec. 2017 & LC08_L1TP_128049_20171220_20171224_01_T1 & 20171220_030332 & 28 \\
\hline Dec. 2017 & LC08_L1TP_128049_20171220_20171224_01_T1 & 20171220_030341 & 28 \\
\hline Dec. 2017 & LC08_L1TP_128049_20171220_20171224_01_T1 & 20171220_030342 & 28 \\
\hline Jan. 2018 & LC08_L1TP_032037_20180120_20180206_01_T1 & 20180120_170400 & 29 \\
\hline Jan. 2018 & LC08_L1TP_032037_20180120_20180206_01_T1 & 20180120_170408 & 29 \\
\hline Jan. 2018 & LC08_L1TP_032040_20180120_20180206_01_T1 & 20180120_170520 & 29 \\
\hline Jan. 2018 & LC08_L1TP_032040_20180120_20180206_01_T1 & 20180120_170521 & 29 \\
\hline Feb. 2018 & LC08_L1TP_128051_20180206_20180221_01_T1 & 20180206_030844 & 23 \\
\hline Feb. 2018 & LC08_L1TP_128051_20180206_20180221_01_T1 & 20180206_030845 & 23 \\
\hline Feb. 2018 & LC08_L1TP_128051_20180206_20180221_01_T1 & 20180206_030846 & 23 \\
\hline Mar. 2018 & LC08_L1TP_022031_20180303_20180319_01_T1 & 20180303_160129 & 26 \\
\hline Mar. 2018 & LC08_L1TP_022032_20180303_20180319_01_T1 & 20180303_160203 & 25 \\
\hline Apr. 2018 & LC08_L1TP_191028_20180420_20180502_01_T1 & 20180420_093038 & 20 \\
\hline Apr. 2018 & LC08_L1TP_191028_20180420_20180502_01_T1 & 20180420_093042 & 20 \\
\hline Apr. 2018 & LC08_L1TP_191028_20180420_20180502_01_T1 & 20180420_093045 & 20 \\
\hline May 2018 & LC08_L1TP_025034_20180527_20180605_01_T1 & 20180527_162522 & 22 \\
\hline May 2018 & LC08_L1TP_025034_20180527_20180605_01_T1 & 20180527_162523 & 22 \\
\hline May 2018 & LC08_L1TP_025034_20180527_20180605_01_T1 & 20180527_162524 & 22 \\
\hline June 2018 & LC08_L1TP_196028_20180626_20180704_01_T1 & 20180626_100108 & 20 \\
\hline June 2018 & LC08_L1TP_196028_20180626_20180704_01_T1 & 20180626_100109 & 20 \\
\hline July 2018 & LC08_L1TP_042036_20180721_20180731_01_T1 & 20180721_180700 & 26 \\
\hline July 2018 & LC08_L1TP_042036_20180721_20180731_01_T1 & 20180721_180701 & 26 \\
\hline Aug. 2018 & LC08_L1TP_192029_20180817_20180829_01_T1 & 20180817_093542 & 22 \\
\hline
\end{tabular}




\section{System Characterization Report on Planet's Dove Classic}

Table 1.1. Radiometric time-series analysis reference datasets.-Continued

[OLI, Operational Land Imager; ID, identifier; _02ef, camera identifier; m, meter]

\begin{tabular}{|c|c|c|c|}
\hline Month & Landsat $80 \mathrm{LI}$ product ID & Dove Classic ID (_02ef) & Time difference $(\mathrm{m})$ \\
\hline Aug. 2018 & LC08_L1TP_192029_20180817_20180829_01_T1 & 20180817_093553 & 22 \\
\hline Aug. 2018 & LC08_L1TP_192029_20180817_20180829_01_T1 & 20180817_093554 & 22 \\
\hline Sept. 2018 & LC08_L1TP_200026_20180926_20181009_01_T1 & 20180926_102341 & 24 \\
\hline Sept. 2018 & LC08_L1TP_200026_20180926_20181009_01_T1 & 20180926_102346 & 24 \\
\hline Sept. 2018 & LC08_L1TP_200027_20180926_20181009_01_T1 & 20180926_102358 & 24 \\
\hline Sept. 2018 & LC08_L1TP_200027_20180926_20181009_01_T1 & 20180926_102359 & 24 \\
\hline Oct. 2018 & LC08_L1TP_025030_20181018_20181031_01_T1 & 20181018_162115 & 24 \\
\hline Oct. 2018 & LC08_L1TP_025030_20181018_20181031_01_T1 & 20181018_162119 & 24 \\
\hline Oct. 2018 & LC08_L1TP_025031_20181018_20181031_01_T1 & 20181018_162137 & 26 \\
\hline Oct. 2018 & LC08_L1TP_025031_20181018_20181031_01_T1 & 20181018_162146 & 26 \\
\hline Nov. 2018 & LC08_L1TP_023034_20181121_20181129_01_T1 & 20181121_161104 & 25 \\
\hline Nov. 2018 & LC08_L1TP_023034_20181121_20181129_01_T1 & 20181121_161109 & 25 \\
\hline Nov. 2018 & LC08_L1TP_023034_20181121_20181129_01_T1 & 20181121_161117 & 25 \\
\hline Dec. 2018 & LC08_L1TP_016040_20181222_20181227_01_T1 & 20181222_153224 & 22 \\
\hline Dec. 2018 & LC08_L1TP_016040_20181222_20181227_01_T1 & 20181222_153225 & 22 \\
\hline Dec. 2018 & LC08_L1TP_016040_20181222_20181227_01_T1 & 20181222_153233 & 22 \\
\hline Jan. 2019 & LC08_L1TP_091085_20190120_20190201_01_T1 & 20190120_234405 & 11 \\
\hline Jan. 2019 & LC08_L1TP_091085_20190120_20190201_01_T1 & $20190120 \_234418$ & 11 \\
\hline Feb. 2019 & LC08_L1TP_041036_20190207_20190221_01_T1 & 20190207_180954 & 18 \\
\hline Feb. 2019 & LC08_L1TP_041036_20190207_20190221_01_T1 & 20190207_180955 & 18 \\
\hline Feb. 2019 & LC08_L1TP_041036_20190207_20190221_01_T1 & 20190207_180956 & 18 \\
\hline Mar. 2019 & LC08_L1TP_180032_20190325_20190403_01_T1 & 20190325_082920 & 16 \\
\hline Mar. 2019 & LC08_L1TP_180032_20190325_20190403_01_T1 & 20190325_082925 & 16 \\
\hline Mar. 2019 & LC08_L1TP_180033_20190325_20190403_01_T1 & 20190325_083005 & 15 \\
\hline Mar. 2019 & LC08_L1TP_180033_20190325_20190403_01_T1 & 20190325_083006 & 15 \\
\hline
\end{tabular}


For more information about this publication, contact: Director, USGS Earth Resources Observation and Science Center 47914 252nd Street

Sioux Falls, SD 57198

605-594-6151

For additional information, visit: https://www.usgs.gov/centers/eros

Publishing support provided by the

Rolla Publishing Service Center 


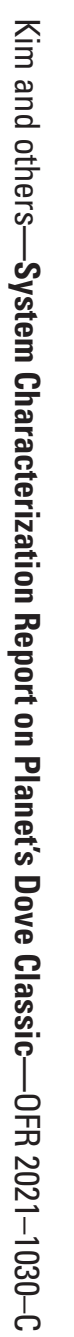

